\title{
Pronoun copying in Dinka Bor and the Copy Theory of Movement
}

\author{
Coppe van Urk ${ }^{1}$
}

Received: 21 April 2016 / Accepted: 5 June 2017 / Published online: 5 January 2018

(C) The Author(s) 2017. This article is published with open access at Springerlink.com

\begin{abstract}
A fundamental question in contemporary minimalist approaches to movement is why copies left by phrasal movement are not realized. Particularly puzzling from this perspective is the observation that pronouns, in a range of environments, appear to function as spell-outs of gaps (e.g. Zaenen et al. 1981; Koopman 1982, 1984; Sells 1984; Engdahl 1985; Pesetsky 1998; Boeckx 2003; Kandybowicz 2007; Holmberg and Nikanne 2008; Harizanov 2014; Sichel 2014), a phenomenon I refer to as pronoun copying. This paper first presents a novel pronoun copying pattern in the Nilotic language Dinka Bor, in which a 3rd person plural pronoun spells out intermediate copies at the verb phrase edge. I then show that Dinka pronoun copying displays two unusual number asymmetries that provide a unique insight into the link between pronoun copying and copy deletion: (i) the pronoun matches only in number, not person, and (ii) only plural DPs initiate copying. Importantly, this number sensitivity mirrors a general asymmetry in the expression of singular and plural. I argue that this parallel reveals that pronoun copying in Dinka reflects partial deletion in a DP copy, deleting everything but the structure that hosts number information. The availability of partial deletion in multiple copy spell-out is shown to follow from an approach to copy deletion based on economy, as developed by Landau (2006). In support of this, I demonstrate that Dinka's asymmetries in fact have their counterparts across pronoun copying constructions and develop a unified account of pronoun copying crosslinguistically.
\end{abstract}

Keywords Multiple spell-out · Copy deletion · Copy Theory of Movement · Pronouns

C. van Urk

c.vanurk@qmul.ac.uk

1 Queen Mary University of London, London, UK 


\section{Introduction}

A key claim of the Minimalist Program is that all structure-building arises by means of a single mechanism, Merge (Chomsky 1995). In this view, movement occurs when one of the inputs to Merge is a syntactic object already present in the structure, resulting in a copy. This idea is often referred to as the Copy Theory of Movement, ${ }^{1}$ and the claim that movement leaves a copy distinguishes the minimalist approach from most other syntactic theories, such as LFG, HPSG, or Categorial Grammar. A challenge in such a framework is that the copies left by phrasal movement do not seem to get realized, even though phrasal movement provides most of the motivation for the Copy Theory of Movement (Chomsky 1995:ch. 3, Sect. 3.5).

At the same time, it has been observed that languages do sometimes spell out multiple copies of a verb when the verb undergoes movement to the left periphery, as the examples from Hebrew, Nupe, and Russian in (1a-c) demonstrate. ${ }^{2}$

\section{Verb copying in Hebrew, Russian, and Nupe:}

a. lirkod, Gil lo yirkod ba-xayim. dance.INF Gil not will-dance in-the-life 'As for dancing, Gil will never dance.'

(Hebrew; Landau 2006:32)

b. Citat' Ivan eë citaet, no nicego ne ponimaet. read.INF Ivan 3FS. ACC reads but nothing not understands 'Ivan DOES read it, but he doesn't understand a thing.'

(Russian; Abels 2001:1)

\section{c. Bi-ba Musa à ba nakàn sasi èsun làzi yin 0 .}

RED-cut Musa FUT cut meat some tomorrow morning PRT FOC

'It is CUTTING that Musa will do to some meat tomorrow morning.'

(Nupe; Kandybowicz 2007:83)

These constructions are found in a wide variety of languages (for an overview, see Kandybowicz 2007:80, for example), and offer support for a copy theory.

In addition, there is one type of multiple spell-out that is consistently found with movement of DPs. In a wide range of constructions, pronouns appear to be able to mark positions in a movement chain. Such phenomena have been documented in at least resumption (2a) (e.g. Zaenen et al. 1981; Engdahl 1982, 1985; Boeckx 2003; McCloskey 2006; Kandybowicz 2007; Sichel 2014), wh-copying constructions (2b) (e.g. Fanselow and Mahajan 2000; Felser 2004; Bruening 2006; Pankau 2013), clitic doubling (2c) (e.g. Anagnostopoulou 2003; Harizanov 2014; Kramer 2014), and subject doubling (2d) (e.g. Van Craenenbroeck and Van Koppen 2002; Holmberg and Nikanne 2008). I refer to such constructions as pronoun copying.

\footnotetext{
${ }^{1}$ I will be not making a distinction here between copy formation and multidominant structures, though see Johnson (2012) for some discussion of how this distinction could be relevant to multiple copy spell-out.

${ }^{2}$ Abbreviations for Dinka: $1 / 2 / 3=1 \mathrm{st} / 2 \mathrm{nd} / 3 \mathrm{rd}$ person, ASSOC $=$ associative plural, $\mathrm{C}=$ complementizer, $\mathrm{CS}=$ construct state, $\mathrm{D}=$ declarative, $\mathrm{FUT}=$ future, $\mathrm{GEN}=$ genitive, $\mathrm{INT}=$ interrogative, $\mathrm{NEG}=$ negation, $\mathrm{NF}=$ non-finite, $\mathrm{OBLV}=$ Oblique Voice, $\mathrm{OV}=$ Object Voice, $\mathrm{P}=$ preposition, $\mathrm{P} / \mathrm{PL}=$ plural, $\mathrm{PASS}=$ passive, $\mathrm{PRF}=$ perfect, $\mathrm{PST}=$ past, $\mathrm{S} / \mathrm{SG}=$ singular, $\mathrm{SV}=$ Subject Voice.
} 
Pronouns can spell out a copy:

a. Bagi-zi Musa gàn [CP gànán a: nì enyà $\mathrm{o}$. man-PL Musa say C 3PL beat drum FOC 'Musa said that THE MEN beat a drum.'

(Nupe; Kandybowicz 2007:124)

b. Tayuwe kt-itom-ups [CP tayuwe apc kt-ol-i malsanikuwam-ok] ? when 2-say-DUB when again 2-thus-go store-LOC 'When did you say you're going to go to the store?'

(Passamaquoddy; Bruening 2006:26)

c. Decata ja običat neja. the.kids 3Fs.ACC love her 'The kids love her.'

d. Ne sai kaikki lapset samat oireet.

3PL got all children same symptoms

'All the children got the same symptoms.'

(Finnish; Holmberg and Nikanne 2008:326)

The question that arises then is what approach to copy deletion can explain both why copy deletion is often obligatory and why, in cases of apparent multiple spell-out, we find the constructions in $(1 \mathrm{a}-\mathrm{c})$ and $(2 \mathrm{a}-\mathrm{d})$.

Nunes $(1995,2004)$ provides an influential account of copy deletion that proposes deletion is necessary to avoid conflicts in the linearization algorithm at PF. This model also offers a route to multiple copy spell-out, on the assumption that copies that are heads may exempt themselves from this calculus through adjunction or cliticization to another head. Such an approach derives verb copying as well as patterns of pronoun copying in which both copies are pronouns, such as $(2 \mathrm{~b}-\mathrm{c})$. A problem for $\mathrm{a}$ linearization-based approach to pronoun copying, however, is that there are pronoun copying constructions in which pronouns spell out copies of full lexical DPs, such as (2a) and (2d). In addition, not all patterns of pronoun copying display clear evidence of cliticization.

In this paper, I present novel evidence for the view that pronouns may spell out DP copies, even of full lexical DPs, from the Nilotic language Dinka (South Sudan). Using data from the Bor dialect, I show that long-distance movement of plural nominals in Dinka requires that the third person plural pronoun ké(ek) appear at each intervening $v \mathrm{P}$ edge, a phenomenon I call ké-copying. As a result, movement of a plural DP leaves a trail of plural pronouns all the way to the gap site $(3 \mathrm{a}-\mathrm{b})$.

(3) Plural pronoun copying at Dinka verb phrase:

a. Ké(ek) áa-cịi Áyèn [ ${ }_{\nu \mathrm{P}}$ ké tị̂i $]$.

3PL 3P-PRF.OV Ayen.GEN 3PL see.NF

'Them, Ayen has seen.'

b. Yè kôoc-kò [CP yíi Bôl [ ${ }_{\nu \mathrm{P}}$ ké luêeel [CP è̀ cíi be.3SG people-which be.OV Bol.GEN 3PL say.NF C PRF.OV Áyèn [ ${ }_{\nu \mathrm{P}}$ ké tî̀in] $\left.\left.]\right]\right]$ ?

Ayen.GEN 3PL see.NF

'Which people does Bol say Ayen has seen?' 
I will present evidence that, in such examples, the pronoun ké represents the spell-out of a fully articulated copy of the moved phrase in an intermediate Spec- $v \mathrm{P}$ position. We will see that the dependencies in $(3 a-b)$ are indistinguishable from other movements in Dinka, in that they are island-sensitive and compatible with reconstruction, and that the plural pronouns occupy the position of an intermediate copy. This means that, like the cases in (2a) and (2d), the pattern in $(3 a-b)$ is a construction in which pronouns spell out copies of full lexical DPs. In addition, we will see that the copied pronoun is not a clitic and occupies a phrasal position, showing that multiple copy spell-out does not need to involve head-adjunction, contra Nunes (1995, 2004; cf. Harizanov 2014; Baker and Kramer 2016).

On this basis, I argue for an approach to copy deletion based on economy, as developed by Landau (2006), in which copy deletion is driven by a pressure to pronounce as little as possible at PF. Such an analysis allows for multiple copy spell-out, if there are PF requirements that prevent deletion. As Landau shows, this view can derive the cases of verb copying in $(1 \mathrm{a}-\mathrm{c})$. In this paper, I demonstrate that an economy approach can also deliver a unified account of pronoun copying, and the mechanisms by which a pronoun can spell out a copy of a full lexical DP. In particular, an economy view of multiple spell-out predicts that the secondary copy must undergo partial deletion if possible, because this will maximize deletion. If we adopt a view of pronouns that treats them as the realization of a DP without a lexical noun (e.g. Postal 1969; Elbourne 2001, 2005), partial deletion of a DP can yield a pronoun (e.g. McCloskey 2006).

A key contribution of this paper is to show that pronoun copying patterns crosslinguistically display two properties that derive from the application of partial deletion, both of which are found in Dinka ké-copying. Specifically, ké-copying displays two asymmetries based on number that I suggest are revealing of the mechanism by which pronouns spell out a DP copy with a richer structure. The first way in which this manifests itself is that copied pronouns in Dinka display a person mismatch effect. 1st and 2nd person pronouns must be copied by the 3rd person plural pronoun instead of an identical pronoun $(4 a-b)$.

Copied pronouns in Dinka only match in number:

a. Wôok cịi $\quad$ Bôl kêek/*wôok tị̂ị.

1PL PRF.OV Bol.GEN 3PL/1PL see.NF 'Us, Bol has seen.'

b. Wêek cíi Bôl kêek/*wêek tî̀i.

2PL PRF.OV Bol.GEN 3PL/2PL see.NF

'You all, Bol has seen.'

In addition, pronoun copying in Dinka has a systematic gap. Only plural DPs trigger copying, while movement of a singular DP cannot be accompanied by a singular pronoun $(5 \mathrm{a}-\mathrm{b})$.

No pronoun copying with movement of a singular noun:

a. Yè yà [CP cíi Bôl [ ${ }_{\nu \mathrm{P}}$ tîiij] $]$ ?

be.3SG who PRF.OV Bol.GEN see.NF

'Who has Bol seen?' 


\section{b. *Yè yà $\left[\mathrm{CP}\right.$ cíi $\quad$ Bôl $\quad\left[{ }_{\nu} \mathrm{P}\right.$ yé(en) tị̂in] $]$ ? be.3SG who PRF.OV Bol.gEN 3SG see.NF 'Who has Bol seen?'}

These effects turn out to mirror a general morphological asymmetry between singular and plural in Dinka. Plurality in Dinka has a consistent cross-paradigmatic spell-out, $k(e)$, while singular is marked in different ways in each paradigm. I argue that this is at work in the form of the 3rd person plural pronoun as well, which I propose is a realization of [plural] only, unlike all other Dinka pronouns. This view of plurality in Dinka captures the number asymmetries in ké-copying through the mechanism of partial deletion: pronoun copying involves only the realization of the part of the copy that encodes number. This explains the person mismatch (person is part of the structure that is deleted), and the lack of copying with singulars (there is no Dinka pronoun that realizes just [singular]).

These Dinka facts then provide novel evidence that the content of a copy may be expressed selectively. In addition, we will see that gaps and person mismatches are not just found in Dinka, but appear in resumption, subject doubling, and wh-copying as well, in Nupe, Finnish, dialects of Dutch, and German, respectively (Kandybowicz 2007; Holmberg and Nikanne 2008; Van Craenenbroeck and Van Koppen 2002; Pankau 2013). On this basis, I argue that all pronoun copying arises by the same mechanism, partial deletion. I present a unified approach to pronoun copying, in which the workings of the copy deletion mechanism is uniform across languages, but may yield pronoun copying if a certain set of conditions are met. Specifically, I demonstrate that, in a partial deletion approach, variation in copying can be captured by appealing only to variation in (i) the distribution of independent PF requirements, (ii) spell-out rules for pronouns and (iii) whether certain functional heads delimit a phase.

The paper is organized as follows. Section 2 introduces the phenomenon of kécopying in Dinka and provides evidence that this pattern comes about because an intermediate copy of successive-cyclic movement through $v \mathrm{P}$ is realized as a pronoun. In Sect. 3, I show that pronoun copying in Dinka displays a gap with singulars as well as a person mismatch. I demonstrate that this sensitivity to plural has a parallel in a general morphological asymmetry between singular and plural in Dinka. On the basis of this, Sect. 4 develops a partial deletion approach to pronoun copying, drawing on Landau's (2006) proposal that copy deletion is driven by economy. In Sect. 5, I show that the person mismatch and the existence of a gap can be found across constructions in which pronouns appear to spell out a gap, and argue on this basis for a unified treatment of these constructions. The picture that emerges is one in which a pronoun can in principle spell out any copy in a movement chain and is not limited to any particular syntactic configuration or construction.

Aside from its consequences for the treatment of pronouns and pronoun copying constructions, this paper functions as an additional argument for successive-cyclic derivations and for the Copy Theory of Movement (Chomsky 1995 et seq.). Because it requires that movement leave copies with an articulated internal structure, the proposal I outline favors an analysis of movement with copies over other ways of modeling long-distance dependencies, such as feature percolation (e.g. Gazdar 1981; Bouma et al. 2001; Neeleman and Van de Koot 2010), or movement with traces 
(Chomsky 1981). My treatment of pronoun copying also provides evidence that features like person and number are hosted on separate projections in the nominal domain and offers insight into how these are organized relative to each other.

\section{Pronoun copying in Dinka Bor}

This section introduces the phenomenon of ké-copying in Dinka Bor, a diagnostic of intermediate movement to the $v \mathrm{P}$ edge identified by Van Urk and Richards (2015). In Dinka, long-distance movement of a plural noun phrase is always accompanied by the appearance of the 3rd person plural pronoun ké(ek) at the edge of each verb phrase on the path of movement. I present evidence that ké-copying results from the spell-out of an intermediate copy. This effect provides novel evidence for the claim that pronouns may act as the spell-out of a gap (e.g. Zaenen et al. 1981; Koopman 1982, 1984; Sells 1984; Engdahl 1985; Pesetsky 1998; Boeckx 2003; Kandybowicz 2007; Holmberg and Nikanne 2008; Harizanov 2014; Sichel 2014).

\subsection{V2 in Dinka}

Dinka is a Nilotic language, spoken in South Sudan. All the data in this paper comes from fieldwork on the Bor dialect. We will see that Dinka has a V2 effect both at the edge of the clause and at the edge of the verb phrase. I focus mainly on $\mathrm{V} 2$ in the $v \mathrm{P}$, which I will hold responsible for ké-copying.

Dinka has a V2 effect at the edge of the clause (Andersen 1991; Van Urk and Richards 2015). In neutral word order, the subject is clause-initial (6a). When a non-subject is fronted, the subject must undergo inversion with regard to the highest verb/auxiliary $(6 b-c){ }^{3}$

The verb is in second position:

a. Àyén à-càm cuîin nẹ̀ păal.

Ayen 3s-eat food $\mathrm{P}$ knife

'Ayen is eating food with a knife.'

b. Cun̂in à-céem Áyèn nè̀ păal.

food 3s-eat.ov Ayen.GEN P knife

'Food, Ayen is eating with a knife.'

c. Păal à-céemè Áyèn cuîin.

knife 3s-eat.OBLV Ayen.GEN food

'With a knife, Ayen is eating food.'

The main focus of this paper, however, is on a V2 effect found in the Dinka verb phrase, which mirrors the V2 effect at the clause edge. In the verb phrase, the highest object must be initial. The verb phrase edge is diagnosed by the position of the lexical verb when it does not move to second position. In (7a), the future auxiliary

\footnotetext{
${ }^{3}$ This is accompanied by a change in case marking of the subject, because Dinka has an Austronesian-style voice system. This is not relevant for the Dinka facts we will be discussing, but see Van Urk (2015) for extensive analysis of voice and case in Dinka.
} 
bé occupies 2nd position and so the non-finite verb tị̂in ('see') is in its base position. We see now that the in situ verb must be preceded by the DP object mìr ('giraffe') (7a-b).

Direct object must precede in situ main verb:

a. Yị̂in bé $\left[{ }_{\nu \mathrm{P}}\right.$ mìir tịin] $]$.

you FUT giraffe see.NF

'You will see a giraffe.'

b. *Yậin bée $\left[v \mathrm{P} \_\right.$tîị mìir]. you FUT see.NF giraffe

'You will see a giraffe.'

This is a V2 effect, because the object occupies a derived position. In sentences with multiple auxiliaries, lower auxiliaries are also non-finite and accompany the main verb (8a). ${ }^{4}$ The object must still appear initially in the verb phrase (8a-b), revealing that it is not in its thematic position.

Object is in a derived position:

a. Tìik à-cé $\quad\left[{ }_{\nu} \mathrm{P}\right.$ cuṇin dâac thàal $]$. woman 3S-PRF food do.quickly.NF cook.NF

'The woman has cooked the food quickly.'

b. *Tìik à-cẹ́ $\quad\left[v \mathrm{P} \_\right.$dâac cuṇin thàal $]$. woman 3S-PRF do.quickly.NF food cook.NF

'The woman has cooked the food quickly.'

In addition to this, all other objects and adjuncts must appear after the main verb. In a ditransitive, either object may appear before the main verb $(9 a-b)$, as long as the other object and any adjuncts follow it.

(9) Only one object before the verb in ditransitives:

a. Yậin cẹe $\left[{ }_{\mathrm{v}} \mathrm{P}\right.$ Bòl gàam cáa ákọ́l].

you PRF Bol give.NF milk afternoon

'You have given Bol milk in the afternoon.'

b. Yậin cẹe $\left[{ }_{\nu} \mathrm{P}\right.$ cáa gàam Bòl ákọ́l].

you PRF milk give.NF Bol afternoon

'You have given milk to Bol in the afternoon.'

Note that this V2 effect ignores subjects. Following Van Urk and Richards (2015) and Van Urk (2015), I propose that we can understand this V2 requirement in featural terms. V2 is established by a $\varphi$-probe on $v$, which agrees with the object and attracts it to Spec- $\nu \mathrm{P}$, as in (10). ${ }^{5}$ For the sake of concreteness, we can think of this $\varphi$-probe

\footnotetext{
${ }^{4}$ Dinka has a wide range of auxiliaries to express meanings associated with adverbs in other languages. See Andersen (2007) for an overview.

${ }^{5}$ Since $\nu \mathrm{P}-$ level V2 in Dinka ignores subjects, I have omitted the subject. We can assume either that the subject occupies a different specifier of $v$ that never interacts with V2 (presumably because $v$ and the subject do not enter into an Agree relation), or that $v \mathrm{P}$ represents a domain below where the subject is generated.
} 
as having an EPP subfeature (e.g. Pesetsky and Torrego 2001), which drives Internal Merge.

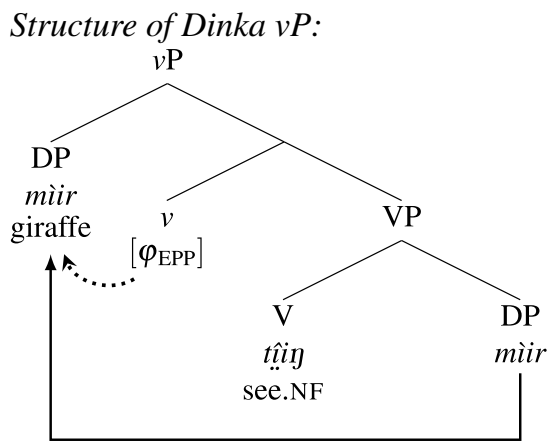

As Van Urk and Richards describe, the $\mathrm{V} 2$ requirements of $\mathrm{C}$ and $v$ are also satisfied by successive-cyclic movement. Moving an object out of a ditransitive, for instance, requires first moving that object to Spec- $v \mathrm{P}(11 \mathrm{a}-\mathrm{d})$, obligatorily satisfying V2 there.

Object movement must transit through Spec-vP:

a. Yè yọ́ cụi môc $\left[v \mathrm{P} \_\right.$yiệện Àyén $]$? be.3SG what PRF.OV man.GEN give.NF Ayen 'What has the man given Ayen?'

b. *Yè yộ cịi môc [ ${ }^{\mathrm{P}}$ Àyén yiệ̣̂̂n]? be.3SG what PRF.OV man.GEN Ayen give.NF 'What has the man given Ayen?'

c. Yè yà cịi môc $\left[{ }^{\mathrm{P}} \_\right.$_ yiệ̣̂̂n kìtáap $]$? be.3SG who PRF.OV man.GEN give.NF book 'Who has the man given the book to?'

d. *Yè yà cịi môc $\quad\left[{ }_{v} \mathrm{P}\right.$ kìtáap yiệện $]$ ?

be.3SG who PRF.OV man.GEN book give.NF

'Who has the man given the book to?'

As in Van Urk and Richards, I assume that these facts reveal the presence of an $\bar{A}$ feature on $v$ that triggers intermediate movement, and so may also attract the phrase that satisfies V2. ${ }^{6}$

These facts also provide evidence that $\nu \mathrm{P}$ is a phase, as in Chomsky (1986 et seq.), and that Spec- $v \mathrm{P}$ functions as an escape hatch position. ${ }^{7}$ The most striking piece of evidence for the role of Spec- $v \mathrm{P}$ in long-distance movement in Dinka comes from a different effect, however, the process of ké-copying, which I turn to now.

\footnotetext{
${ }^{6}$ To explain why intermediate movement must satisfy V2 in Dinka, Van Urk and Richards (2015) adopt an economy condition, Multitasking, that forces all probes on a head to target the same goal if possible.

${ }^{7}$ Similar effects are found at the CP edge. I discuss these in Sect. 4.4, which addresses the question of why there is no pronoun copying at the clause edge.
} 


\subsection{Introducing $k e ́$-copying}

Intermediate movement in Dinka is also associated with a multiple copy spell-out effect. Movement of a plural DP in Dinka triggers the appearance of the 3rd person plural pronoun $k e ́(e k)$ at the edge of each $v \mathrm{P}$ on the path of movement. This happens with all instances of long-distance movement, including topicalization, as in (12a), relativization, as in (12b), or the $w h$-cleft in (12c). ${ }^{8}$ As evident in (12a-c), ké-copying is found with all types of DP, whether pronouns or lexical DPs.

Movement of plural nominal triggers pronoun copying:

a. Kêek áa-cíi Áyèn [ $\nu_{\mathrm{P}}$ ké tîị].

3PL 3P-PRF.OV Ayen.GEN 3PL see.NF

'Them, Ayen has seen.'

b. Bòl à-cé rọ̀gọr [CP cè̀ $\quad\left[{ }_{\nu} \mathrm{P}\right.$ ké lâat] $]$ tị̂iy.

Bol 3S-PRF men PRF.3SG 3PL insult.NF see.NF

'Bol has seen the men he has insulted.'

c. Yè kôoc-kò [CP cíi $B$ Bôl [ ${ }_{\nu \mathrm{P}}$ ké tîin] $]$ ?

be.3SG people-which PRF.OV Bol.GEN 3PL see.NF

'Which people has Bol seen?'

The 3rd person plural pronoun appears in the Spec- $v \mathrm{P}$ position, and seems to satisfy the V2 property of the verb phrase. We did not see evidence of pronoun copying in the previous section, because it displays a number asymmetry: it is limited to plural nominals. Movement of a singular DP is not accompanied by a copied pronoun (13a). Adding a singular pronoun at the $v \mathrm{P}$ edge just leads to ungrammaticality (13b). ${ }^{9}$

No pronoun copying with movement of a singular noun:
a. Yè yà [CP cîi Bôl [ ${ }_{\nu \mathrm{P}}$ tî̀i $\left.]\right]$ ?
be.3SG who PRF.OV Bol.GEN see.NF
'Who has Bol seen?'
be.3SG who PRF.OV Bol.gEN 3SG see.NF
'Who has Bol seen?'
b. *Yè yà [CP cíi Bôl [

Pronoun copying happens successively in cases of long-distance extraction. A copied 3rd person plural pronoun appears at every $v \mathrm{P}$ edge on the path of movement, as the examples in $(14 \mathrm{a}-\mathrm{b})$ demonstrate.

\section{Ké-copying targets each verb phrase edge:}

a. Yè yà [CP yíi Bôl [vP luêeel [CP è̀ cíi Ál Ayèn
be.3SG who be.OV Bol.GEN say.NF C PRF.OV Ayen.GEN
[vP tîiin]]]]?
see.NF
'Who does Bol say Ayen has seen?'

\footnotetext{
${ }^{8}$ See Van Urk (2015) for a description of the various types of long-distance movement in Dinka.

${ }^{9}$ This pattern cares only about grammatical plurality of the moving DP. Ké-copying is required regardless of whether single or multiple events are described.
} 
b. Yè kôoc-kò $\quad[\mathrm{CP}$ yịi $\quad$ Bôl $\quad$ [vP ké luêeel [CP è̀ be.3SG people-which be.Ov Bol.gen 3PL say.NF C cịi Áyèn [ ${ }_{\nu \mathrm{P}}$ ké tîiin]]]]? PRF.OV Ayen.gEN 3PL see.NF 'Which people does Bol say Ayen has seen?'

In addition, pronoun copying is obligatory, so that omitting either instance of ké(ek) in an example like (14b) is ungrammatical (15). ${ }^{10}$

Omitting ké(ek) is ungrammatical:

Yè kôoc-kò [CP yịi $\quad$ Bôl [ [vP *(ké) luêeel [CP è̀ cíi

be.3SG people-which be.OV Bol.gen 3PL say.NF C PRF.OV

Áyèn $\left[{ }_{\nu \mathrm{P}} *(\mathbf{k e ́})\right.$ tî̀ì] $\left.\left.]\right]\right]$ ?

Ayen.GEN 3PL see.NF

'Which people does Bol say Ayen has seen?'

I refer to this phenomenon as ké-copying. I will argue that it reflects the realization of an intermediate copy left by successive-cyclic movement in Spec- $v \mathrm{P}$, and is driven by the V2 property of $v$. In other words, for an example like (15), ké-copying involves the configuration in (16).

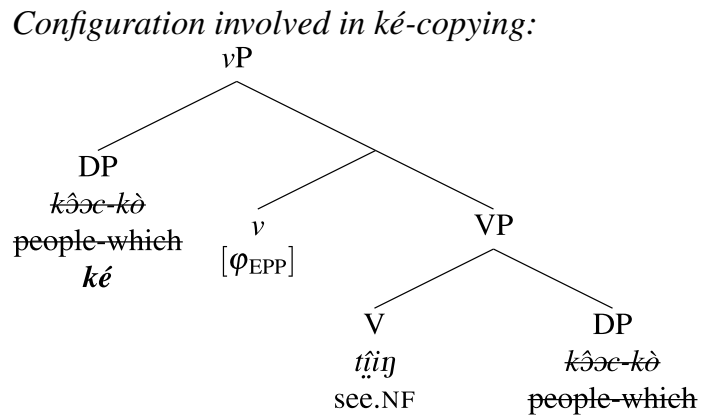

Importantly, this means that copied ké functions as the spell-out of a lexical DP, like $k \hat{s} x c-k o ́$ ('which people') in the tree above. In the rest of this section, I motivate the different aspects of the multiple copy spell-out analysis in (16), starting with the proposal that $k e$-copying involves copying of a pronoun.

\subsection{Copied $k e ́$ is a pronoun}

Like all Dinka pronouns, the third person plural pronoun has a full version (kêek) and a phonologically reduced form (ké), with a short vowel and no coda consonant $(17 \mathrm{a}-\mathrm{b})$.

\footnotetext{
${ }^{10}$ There may be some variation across speakers in this respect. The two Dinka speakers I worked with consistently require it, but ké-copying is described as optional for the Agar dialect by Andersen (1991:276277). See fn. 46 for suggestions on how to handle speakers for whom ké-copying is optional. Note also that Andersen's two examples of ké-copying contain the short form ké.
} 
Pronouns have full and reduced forms:

a. Ròooor áa-cé ké tị̂in.

men 3P-PRF 3PL see.NF

'The men have seen them.'

b. Rọooor áa-cẹ ｅ̂ek tị̂in.

men 3P-PRF 3PL see.NF

'The men have seen them.'

Although the full form appears to convey some emphasis, these pronouns can be used interchangeably in most instances. Both can be coordinated, for instance (18a-b) (cf. Cardinaletti and Starke 1999; Déchaine and Wiltschko 2002).

Full and reduced pronouns can both be coordinated:

a. Bòl à-cé Àyén kù̀ kêek tîị.

Bol 3S-PRF Ayen and 3PL see.NF

'Bol has seen Ayen and them.'

b. Bòl à-cé Àyén kù̀ ké tị̂ị.

Bol 3S-PRF Ayen and 3PL see.NF

'Bol has seen Ayen and them.'

We see the same variation in pronoun copying, so that both the reduced and full form may accompany any particular instance of movement $(19 \mathrm{a}-\mathrm{d})$, without any apparent difference in interpretation.

Ké-copying may involve full or reduced form:
be.3SG people-which PRF.OV Bol.GEN 3PL see.NF
'Which people has Bol seen?'
a. Yè kồc-kò [CP cíi Bôl ké tî̀i $]$ ?
b. Yè kôoc-kò [CP cíi $\quad$ Bôl kêek tị̂in]?
be.3SG people-which PRF.OV Bol.GEN 3PL see.NF
'Which people has Bol seen?'
c. Kêek áa-cịi Áyèn ké tịị.
3PL 3P-PRF.OV Ayen.GEN 3PL see.NF
'Them, Ayen has seen.'
d. Kêek áa-cíi Áyèn kêek tî̀i
3PL 3P-PRF.OV Ayen.GEN 3PL see.NF
'Them, Ayen has seen.'

This variation extends to long-distance movement. With multiple instances of kécopying, any of them may appear as the full form of the pronoun, apparently without constraints $(20 \mathrm{a}-\mathrm{c})$.

(20) No constraints on full/reduced forms in ké-copying:

a. Yè kôoc-kò $\quad\left[\mathrm{CP}\right.$ yụi $\quad$ Bôl $\quad{ }_{\nu \mathrm{P}}$ kêek luêeel $[\mathrm{CP}$ è be.3SG people-which be.OV Bol.GEN 3PL say.NF $\ddot{\mathrm{C}}$

cịi Áyèn [ ${ }_{\nu \mathrm{P}}$ kêek tî̀ì] $\left.\left.]\right]\right]$ ?

PRF.OV Ayen.GEN 3PL see.NF

'Which people does Bol say Ayen has seen?' 
b. Yè kôoc-kò [CP ỵ̂ii Bôl $\quad\left[{ }_{\nu}\right.$ p ké luêeel $[\mathrm{CP}$ è be.3SG people-which be.OV Bol.GEN 3PL say.NF C cíi Áyèn $\quad\left[{ }_{\nu} \mathrm{P}\right.$ kêek tî̀in] $\left.\left.]\right]\right]$ ?

PRF.OV Ayen.GEN 3PL see.NF

'Which people does Bol say Ayen has seen?'

c. Yè kôoc-kò [CP yíi Bôl [ ${ }_{\nu \mathrm{P}}$ kêek luêeel [CP è̀ be.3SG people-which be.ov Bol.gen 3PL say.NF C cíi Áyèn [ ${ }_{\mathrm{v}} \mathrm{P}$ ké tîìn] $\left.]\right]$ ? PRF.OV Ayen.GEN 3PL see.NF 'Which people does Bol say Ayen has seen?'

This similarity in form suggests that copied ké(ek) is an instance of the 3rd person plural pronoun. In addition, it suggests that copied ké(ek) is not a clitic. Dinka is an overwhelmingly monosyllabic language. Most lexical roots are limited to a $\mathrm{C}(\mathrm{G}) \mathrm{V}(\mathrm{V}) \mathrm{C}$ template (where $\mathrm{G}=$ glide), permitting one vowel length contrast in their inflectional paradigm. As a result, copied ké is no more reduced in form then than many lexical nouns, verbs, and adjectives. ${ }^{11}$ All true affixes, for example, lack a coda consonant (as evident in the paradigms in Sect. 3.2).

That copied ké is not a clitic is also evident in the fact that it is free-standing, like regular pronouns. Copied ké often immediately precedes the verb, as in (21a). This does not have to be the case, however. Copied ké can surface also before an object in Spec- $v \mathrm{P}$ when a plural adjunct moves out of the $v \mathrm{P}(21 \mathrm{~b})$. In fact, copied ké can be followed by nothing at all, when the verb moves to 2 nd position $(21 \mathrm{c})$.

Copied pronoun is free-standing:

a. Yè kôoc-kò $\quad\left[\mathrm{CP}\right.$ cíi $\quad$ Bôl $\quad\left[{ }_{\nu \mathrm{P}}\right.$ ké(ek) tî̀in] $]$ ? be.3SG people-which PRF.OV Bol.GEN 3PL see.NF 'Which people has Bol seen?'

b. Yè yạan-kò [CP cíi $\quad$ Bôl [ ${ }^{\mathrm{P}}$ ké(ek) Àyén tuòoc]]? be.3SG places-which PRF.OV Bol.GEN 3PL Ayen send.NF 'Which places has Bol sent Ayen to?'

c. Yè kóoc-kò $\left[\mathrm{CP}\right.$ nhiéer Bôl ${ }_{\nu \mathrm{P}}$ ké(ek) $\left.]\right]$ ? be.3SG people-which love.OV Bol.GEN 3PL 'Which people does Bol love?'

These facts demonstrate that ké is free-standing and not associated with the verb. Ké is not the realization of a functional head in the extended projection of the verb, and is not cliticized onto one, because then it should move along with the verb when the verb moves into the left periphery. Instead, its position simply reflects the position of a specifier of $v$. The fact that copied $k e$ is a non-clitic element is an important one, because it is one of the conclusions that favor the partial deletion analysis I will develop over an alternative in which multiple copy spell-out with DPs is driven by cliticization (e.g. Nunes 1995, 2004; Harizanov 2014; Kramer 2014; Baker and Kramer 2016).

\footnotetext{
${ }^{11}$ The only way in which some roots are bigger than kêek is that some roots contain a superlong vowel.
} 


\subsection{Ké-copying tracks intermediate movement}

Having established then that ké-copying signals the presence of a true pronoun, let me show in more detail that it tracks intermediate movement. Ké-copying reliably appears with movement of any plural noun phrase that undergoes intermediate successive-cyclic movement to the verb phrase edge, regardless of grammatical function. For example, plural VP-modifiers trigger ké-copying, just like objects $(22 \mathrm{a}-\mathrm{b}) .^{12}$

Ké-copying with plural modifiers:
a. Yè yạan-kò [CP cîi
Bôl [ ${ }_{v \mathrm{P}}$ ké Àyén tuòoc]]?
be.3sG places-which PRF.OV Bol.GEN 3PL Ayen send.NF
'Which places has Bol sent Ayen to?'
b. Yè tóony kê díi [CP cíi Bôl [ ${ }^{\mathrm{P}}$ ké cun̂in thàal]]? be.3SG pots many how PRF.OV Bol.GEN 3PL food cook.NF 'How many pots has Bol cooked food with?'

Like objects, such modifiers trigger successive ké-copying when undergoing longdistance movement, as the examples in $(23 \mathrm{a}-\mathrm{b})$ attest.

Successive ké-copying with plural modifiers:

a. Yè yạan-kò [CP yá $\quad\left[{ }_{\nu \mathrm{P}}\right.$ ké luêeel [CP è̀ cíi

be.3SG places-which be.2SG 3PL say.NF C PRF.OV

Bôl [ $\quad$ P ké Àyén tuòoc]]]]?

Bol.gen 3PL Ayen send.NF

'Which places do you say that Bol has sent Ayen to?'

b. Yè tọony ké díi [CP yá [ ${ }_{\nu \mathrm{P}}$ ké luêeel [CP è̀ cịi

be.3SG pots many how be.2SG 3PL say.NF C PRF.OV

Bôl [ $\quad{ }_{\nu} \mathrm{P}$ kê cuînin thàal] $\left.\left.]\right]\right]$ ?

Bol.GEN 3PL food cook.NF

'How many pots do you say that Bol has cooked food with?'

All plural modifiers trigger ké-copying in this fashion. A plural temporal adjunct, for instance, also requires a copied ké (24a), as does a plural instrumental (24b). ${ }^{13}$

Ké-copying with plural modifiers:
a. Yè thèck-kò [CP cíi
Bôl [ $\left[{ }_{\mathrm{P}} \mathrm{P}\right.$ ké bọ̀ jạal $\left.]\right]$ ?
be.3SG times-which PRF.OV Bol.gEN 3PL come.NF leave.NF
'At which times has Bol left?'

\footnotetext{
${ }^{12}$ In Dinka Bor, extraction of modifiers is usually accompanied by the Oblique Voice form of the verb. As evident in these examples, auxiliaries may optionally lack this marking, surfacing in the Object Voice form instead. See Van Urk (2015:ch. 3, Sect. 2.5) for description and discussion.

${ }^{13}$ These facts seem to show that at least PPs that contain a lexical noun must be generated inside $v \mathrm{P}$ in Dinka. This could be taken to be related to the fact that all moved phrases have to become nominal, as described in Van Urk (2015). Specifically, we could take this as evidence that what appear to be modifiers actually must be generated as nominals in a high applicative construction to be able to be extracted. This would also explain how the preposition comes to be omitted. See Van Urk (2015) for more discussion.
} 


\section{b. Yè kạ̀yọ́ [CP cịi $\quad$ Bôl $\quad\left[{ }^{p P}\right.$ ké bọ̀ jạall]]? be.3SG what.things PRF.OV Bol.GEN 3PL come.NF leave.NF 'Which things has Bol used to leave with?'}

Importantly, the only plural phrases that do not trigger ké-copying with $\bar{A}$-movement within a clause are subjects. A plural subject in Spec-CP, for example, cannot be doubled by a copied ké (25a). Similarly, relativization of a subject may not be accompanied by ké-copying (25b).

Subjects are not doubled by a plural ké locally:

a. Ròoor áa-cé (*ké) yịin tîị.

men 3P-PRF 3PL you see.NF

'The men have seen you.'

b. Yè kôoc-kò [CP cé (*ké) cuîin câam]?

be.3SG people-which PRF 3PL food eat.NF

'Which people have eaten food?'

These facts show that ké-copying is linked to the $\mathrm{V} 2$ requirement of $v$. As mentioned in Sect. 2.1, subjects do not count for $v \mathrm{P}-$ level V2 in Dinka, presumably because they do not enter into an Agree relation with $v$.

In support of this, we see that subjects do trigger ké-copying when they are undergoing long-distance movement. When a subject moves long-distance, a copied ké is still banned at the $v \mathrm{P}$ edge the subject is generated at, but ké-copying is obligatory at every subsequent verb phrase (26a-b). (Note that, since local subjects do not trigger $k e$-copying $(25 \mathrm{a}-\mathrm{b})$, the 1 st person plural matrix subject cannot be the source of ké-copying.)

Plural subjects are doubled by ké in higher clauses:

a. Ròogor áa-yùuukù $\left[{ }_{\nu P}\right.$ ké tàak [CP cé $\quad\left[{ }_{\nu P}\right.$ (*ké) yị̂n tị̂ị]]]. men 3P-be.1PL 3PL think.NF PRF 3PL you see.NF 'The men, we think have seen you.'

b. Yè kôoc-kò $\quad\left[\mathrm{CP}\right.$ yụ̀ukù $\left[{ }_{\nu \mathrm{P}}\right.$ ké tàak $\quad\left[\mathrm{CP}\right.$ càm $\left[{ }_{v \mathrm{P}}\left({ }^{*}\right.\right.$ (*ké) be.3SG people-which be.1PL 3PL think.NF eat 3PL cuîin]]]]?

food

'Which people do we think are eating food?'

A particularly nice piece of evidence for the structural sensitivity of ké-copying comes from extraction out of clausal subjects. The verb nhóm mâạ ('to forget, lit. to lose one's head') takes a clausal subject (27a), which usually appears extraposed (and, like other subjects, is outside the $v \mathrm{P}$ ). In a reversal of the pattern in (26a-b), long-distance movement from such an extraposed clausal subject requires ké-copying in the lower clause, as expected, but the absence of ké-copying in the higher clause (27b)..$^{14}$

\footnotetext{
${ }^{14}$ This pair of examples also shows that Dinka allows extraction out of an extraposed clausal subject. Note that Dinka generally allows extraction out of extraposed clauses (see also Van Urk and Richards 2015).
} 
No ké-copying in higher clause with extraction out of clausal subject:

a. À-cé $\quad\left[{ }_{v \mathrm{P}}\right.$ wôok muộọr nhîim] [CP è̀ wôok ệ-cè̀ kồc-kè̀ 3S-PRF 1PL lose.NF heads $\ddot{C} 1 \mathrm{PL}$ PST-PRF people-these tị̂in].

see.NF

'We have forgotten that we had seen these people.'

b. Yè kôoc-kò cé $\left[{ }^{\mathrm{P}}\right.$ (*ké) wôok muộọr nhîîm] [CP è̀ be.3SG people-which PRF 3PL 1PL lose.NF heads $\stackrel{\mathrm{C}}{\mathrm{C}}$

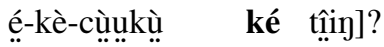
PST-PL-PRF. 1PL 3PL see.NF

'Which people have we forgotten that we had seen?'

This contrast follows if ké-copying reflects intermediate movement to Spec- $v \mathrm{P}$. Subjects are not in the domain of verb phrase V2 and so movement out of a subject should not require stopping off at its $v \mathrm{P}$ edge.

We can conclude from these facts that ké-copying is a consequence of intermediate movement to the edge of the verb phrase. As noted also by Van Urk and Richards (2015), ké-copying then functions as additional evidence for successive-cyclic derivations through $v \mathrm{P}$ edges (Chomsky 1986 et seq.).

\subsection{Ké-copying is spell-out of a copy}

Let me now provide arguments for the claim that dependencies with ké-copying involve movement. It is important to show, first of all, that dependencies with kécopying behave like all other instances of movement in Dinka. Because ké-copying is limited to plurals, we can compare movement with ké-copying to movement without it, by comparing movement of a plural to a movement of a singular. First of all, as already noted, all movement, accompanied by ké-copying or not, satisfies the $\mathrm{V} 2$ property of intervening $\mathrm{CP}$ and $v \mathrm{P}$ edges, providing evidence for a successivecyclic derivation. In addition, as the examples in (28a-b) demonstrate, all movement, whether accompanied by ké-copying or not, is sensitive to islands.

Ké-copying is island-sensitive:
a. *Yè yọ́ [CP cíi Áyèn [DP ràaan [CP mè̀r be.3SG what PRF.OV Ayen.GEN person.CS1 decorate
]] tị̂in]? see.NF

'What has Ayen seen someone [who is decorating it]?'
b. *Yè kôoc-kò [CP cíi $\quad$ Bôl (ké) [DP ràaan [CP
be.3SG people-which PRF.OV Bol.GEN (3PL) person.CS1
cẹ ké cuị̂in câam]] tîị]?
PRF 3PL food eat.NF see.NF
'Which people has Bol seen someone who has eaten food with them?'

In further support of the idea that the syntax of movement is the same regardless of whether ké-copying takes place, observe that whether movement reconstructs is inde- 
pendent of ké-copying. Using Dinka's Condition A anaphor, movement can be shown to reconstruct for local (29a), long-distance (29b), and intermediate binding (29c).

Movement reconstructs for anaphor binding:
a. Ròt-dé ì̀-cè̀i
self-SG.3SG 3S-PRF.3SG love.NF
'Herself/himself, she/he has loved.'
b. Ròt-déi à-yụ̀ukụ̀ tàak [CP è̀ cẹ̀i nhiâar]. self-SG.3SG 3s-be.1PL think.NF C PRF.3SG love.NF 'Herself/himself, we say that she/he has loved.'
c. Ròt-dé à-cẹ̀i tàak [CP ẹ̀ cừukù nhiâar]. self-SG.3SG 3S-PRF.3SG think.NF C PRF.1PL love.NF 'Herself/himself, she/he has thought that we have loved.'

We find the same facts with ké-copying. When the plural version of the anaphor topicalizes, it is accompanied by ké-copying just like other plural DPs. In such constructions, the anaphor can still reconstruct to the same positions, ${ }^{15}$ as the examples in $(30 \mathrm{a}-\mathrm{c})$ attest. $^{16}$

\section{Ké-copying allows reconstruction:}

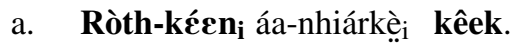
self-PL.3PL 3P-love.3PL 3PL

'Themselves, they love.'

b. Ròth-kéen áa-yụ̀ụù̀ ké luêeel [CP ẹ̀ nhiárkẹ̀i kêek]. self-PL.3PL 3P-be.1PL 3PL say.NF C love.3PL 3PL 'Themselves, we say that they love.'

c. Ròth-kéen áa-ỵ̣ikẹ̀i ké luêeel [CP ẹ̀ nhiécr Bôl kêek]. self-PL.1PL 3P-be.3PL 3PL say.NF C love.OV Bol.GEN 3PL 'Themselves, they say that Bol loves.'

There is no discernible effect of ké-copying then on the interpretation of long-distance movement. This follows if copied ké simply diagnoses the location of an intermediate copy of successive-cyclic movement.

Another piece of evidence that suggests that ké should be treated as the result of movement comes from its position. As we saw in Sect. 2.1, only one DP may overtly appear at the left edge of the Dinka verb phrase. The sole exception to this in Dinka is the process of ké-copying. As we have already seen, when a copied ké is left by adjunct extraction, it precedes the object that occupies Spec- $v \mathrm{P}(31 \mathrm{a}-\mathrm{b}) .{ }^{17}$

\footnotetext{
${ }^{15}$ It is important here that reconstruction effects co-occur with island-sensitivity, since Guilliot and Malkawi (2006) have shown that there is a class of resumptive pronouns, such as weak pronouns in Jordanese Arabic, that display apparent reconstruction effects in islands, through a mechanism of NP deletion. For this reason, reconstruction is only a reliable diagnostic for movement if it co-occurs with island-sensitivity.

${ }^{16}$ Note that topicalization of the anaphor is only possible if it is accompanied by a pronominal possessor co-indexed with the antecedent. It is also possible to use the anaphor without a possessor in the base position, but then topicalization is impossible.

${ }^{17}$ Note that some speakers must have a resumptive pronoun thịn ('in it', roughly) in (31a).
} 
Ké may appear before object in violation of $V 2$ :
a. Yè yạan-kò [CP cíi Bôl [ ${ }^{\mathrm{P}}$ ké Àyén tuòoc $]$ ? be.3SG places-which PRF.OV Bol.gEN 3PL Ayen send.NF 'Which places has Bol sent Ayen to?'
b. Yè tóony kê díi [CP cíi Bôl [ ${ }^{\mathrm{P}}$ ké cun̂in thàal]]? be.3SG pots many how PRF.OV Bol.GEN 3PL food cook.NF 'How many pots has Bol cooked food with?'

This is the only instance in which two DPs appear at the left edge of the verb phrase in Dinka (setting aside the subject, which does not count for the calculus of V2). Dinka does not allow other nominals, adjuncts, or adverbs to surface in between an in situ subject and an object in Spec- $v$ P. As a result of this, there is a clear contrast between copied and independent instances of ké(ek). Independent uses of the third person plural pronoun obey the $\mathrm{V} 2$ restriction: they may only appear at the $v \mathrm{P}$ edge by themselves (32a), and not alongside another object (32b).

Independent ké(ek) cannot occur between subject and object:
a. Bòl à-cée [ $v_{\mathrm{P}} \mathbf{k e ́}(\mathbf{e k}) \mathrm{yi} \hat{\underline{e ̣ ̂ n ~}}$ kìtáap].
Bol 3S-PRF 3PL give.NF book
'Bol has given them a book.'
b. *Bòl à-cẹ́ [ [vP ké(ek) kìtáap yiệc̣n].
Bol 3S-PRF 3PL book give.NF
'Bol has given them a book.'

We can make sense of these facts if copied ké is the realization of an intermediate copy. As previously suggested, there are two distinct featural triggers for $\mathrm{V} 2$ on $v$, a $\varphi$-probe and an $\bar{A}$-feature, allowing for the creation of an additional specifier at the $\nu \mathrm{P}$ edge. In this view, the position of copied ké in an example like (31b) reflects the position of an outer specifier, as schematized in (33). ${ }^{18}$

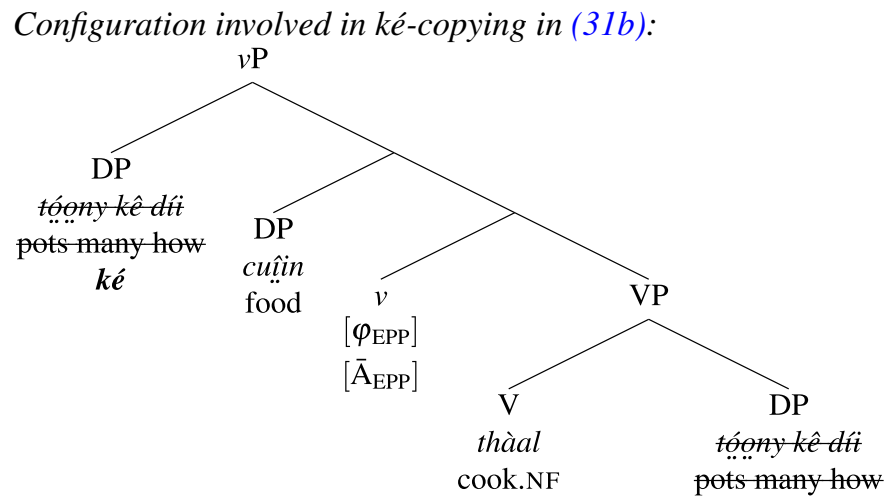

The position of copied ké in such examples also functions as an argument against an approach that takes it to be a clitic or a functional head, because it shows that

\footnotetext{
${ }^{18}$ An interesting question is why copied ké must reside in the outer specifier. For the sake of concreteness, we can attribute this to the order in which the different probes on $v$ are activated.
} 
copied ké does not surface in the position of $v$, but on the edge of that projection. In contrast, the facts represented in (33) follow if copied ké is the spell-out of a copy, because its position then directly reflects the position of the outer specifier of $v$.

I conclude then that ké-copying in Dinka is the realization of a copy left by intermediate successive-cyclic movement to the $v \mathrm{P}$ edge. In this way, Dinka provides novel evidence that pronouns can mark positions in a movement dependency and act as realizations of gaps (e.g. Zaenen et al. 1981; Koopman 1982, 1984; Sells 1984; Engdahl 1985; Pesetsky 1998; Kandybowicz 2007; Holmberg and Nikanne 2008; Harizanov 2014; Sichel 2014). Importantly, this type of construction cannot be captured by an approach to multiple copy spell-out along the lines of Nunes $(1995,2004)$. First of all, ké-copying occurs with complex DPs as well as pronouns. In addition, copied ké does not behave like a clitic or an adjoined head. As with other constructions of this type, the question arises then how a pronoun can be created from a DP copy, which may be complex and contain all sorts of additional material. In the rest of paper, I show that ké-copying displays two unusual asymmetries based on number that offer a unique insight into the mechanisms behind pronoun copying. In particular, we will see that ké-copying's unusual sensitivity to plurality receives a straightforward explanation if pronoun copying arises through partial deletion.

\section{Pronoun copying and number in Dinka}

In this section, I show that ké-copying has an unusual sensitivity to plurality, which expresses itself in two asymmetries. First, pronoun copying in Dinka shows a gap with singulars, as already discussed. In addition to this, ké-copying only matches the antecedent DP in number, and systematically displays a person mismatch. These asymmetries mirror a general asymmetry between singular and plural in Dinka, also evident in the pronoun paradigm: plurality is consistently marked in the same way across paradigms, with the morpheme $k(e)$. In contrast, there is no cross-paradigmatic marking for singular. I will later argue that two asymmetries provide an important clue for the proper analysis of pronoun copying. In particular, we will see that these asymmetries can be captured in an account that treats ké-copying as the realization of only the subpart of a copy that expresses number.

\subsection{Number asymmetries in ké-copying}

A key characteristic of Dinka pronoun copying is its sensitivity to plurality. As previously mentioned, for example, movement of a singular DP never triggers copying $(34 a-b)$.

Ké-copying is limited to plurals:

a. Yè kôoc-kó [CP cíi Bôl [ ${ }^{\mathrm{P}}$ ké tîij]]?

be.3SG people-which PRF.OV Bol.GEN 3PL see.NF

'Which people has Bol seen?' 


\section{b. Yè yà [CP cịi Bôl $\left[{ }_{\nu \mathrm{P}}(* \mathbf{*}\right.$ é $)$ tîị $\left.]\right]$ ? be.3SG who PRF.OV Bol.GEN 3SG see.NF 'Who has Bol seen?'}

I will refer to a restriction of this type, in which only a subset of possible antecedents trigger pronoun copying, as a gap. We will later see, in Sect. 5.2, that gaps can be found in other pronoun copying constructions as well.

The second number-related asymmetry found in Dinka pronoun copying is that the copied pronoun only matches the moved DP in number, and not in person. We see this when a 1st or 2nd person plural pronoun is topicalized across the $v \mathrm{P}$ edge. Pronoun copying is still triggered, but it is the third person plural pronoun ké(ek) that appears $(35 \mathrm{a}-\mathrm{b})$.

Ké-copying does not match person:
a. Wôok cịi Áyèn $\quad\left[{ }_{\nu} \mathrm{P}\right.$ ké(ek) tị̂in].
$1 \mathrm{PL} \quad$ PRF.OV Ayen.GEN 3PL see.NF
'Us, Ayen has seen.'
2PL PRF.OV Ayen.GEN 3PL see.NF
'You all, Ayen has seen.'
b. Wêek cíi Áyèn $\quad\left[{ }_{\nu} \mathrm{P}\right.$ ké(ek) tị̂ị].
c. Kêek áa-cîi $\quad$ Áyèn $\quad\left[{ }_{\nu \mathrm{P}}\right.$ ké(ek) tî̀ị].
3PL 3P-PRF.OV Ayen.GEN 3PL see.NF
'Them, Ayen has seen.'

Using a copied pronoun with matching person features is impossible (36a-b).

Copied pronouns cannot be 1st or 2nd person:
a. *Wôok cíi Áyèn [ ${ }_{\nu \mathrm{P}}$ wó(ok) tî̀i ].
1PL PRF.OV Ayen.GEN 1PL see.NF
'Us, Ayen has seen.'
b. *Wêek cíi Áyèn [ $\quad$ P wé(ek) tîị].
2PL PRF.OV Ayen.GEN 2PL see.NF
'You all, Ayen has seen.'

1st and 2nd person plural pronouns pattern like 3rd person plural nominals in every respect for ké-copying. As a further illustration of this, we see that long-distance movement of these pronouns triggers pronoun copying at each edge (37a-b).

1st/2nd person pronouns can trigger successive ké-copying:
a. Wôsk yíi Bôl $\quad\left[{ }_{\nu \mathrm{P}}\right.$ ké luêeel [CP è̀ cè̀ $\quad\left[{ }_{\nu \mathrm{P}}\right.$ ké tîiin]]]. 1PL be.OV Bol.gEN 3PL say.NF C PRF.3SG 3PL see.NF 'Us, Bol says that he has seen.'
b. Wêek yíi Bôl [ ${ }^{\mathrm{P}}$ ké luêeel [CP è̀ cẹ̀ $\quad\left[{ }^{\mathrm{P}}\right.$ ké tîị]]]. 2PL be.OV Bol.gen 3PL say.NF C PRF.3SG 3PL see.NF 'You all, Bol says that he has seen.'

If third person is the default value for person, this shows that ké-copying only displays matching in number. I refer to this asymmetry as a person mismatch, and we 
will see that, like gaps in pronoun copying, this asymmetry too can be found across pronoun copying constructions (Sect. 5.1).

These asymmetries are unexpected, and provide an important clue as to the mechanism that allows a pronoun to realize a DP copy. In particular, I show in the next section that they mirror a general morphological asymmetry between singular and plural in Dinka, which points to a partial deletion account.

\subsection{Plural marking in Dinka}

Ké-copying's sensitivity to plurality parallels a general proclivity in the language for the signaling of plurality. The same morpheme, $k(e)$, functions as plural inflection in a range of morphosyntactic environments. In contrast, although some paradigms have a regular way of marking singular, none of these have predictable cross-paradigmatic uses. I capture this by proposing that the morpheme $k(e)$ is a general spell-out of plural, unspecified for morphosyntactic context. I then argue that this allows us to understand why the pronoun ké(ek) might differ from Dinka's other pronouns. The 3rd person plural pronoun is the only pronoun that can be analyzed as a pure expression of number, with no overt person morpheme.

Let me first motivate the idea that $k(e)$ is a general plural marker in Dinka, employed across a variety of paradigms. The first of these paradigms concerns an agreement prefix I will refer to as the declarative or interrogative particle. This prefix appears on the second position verb/auxiliary and expresses $\varphi$-agreement with the nominal that satisfies clause-level V2 (38a-b).

Prefix on V2 position expresses $\varphi$-agreement:

a. Mòc à-cé y yịin tî̀i

man 3S-PRF you see.NF

'The man has seen you.'

b. Miècr áa-càa ké tî̀ị.

giraffes 3P-PRF.1SG 3PL see.NF

'The giraffes, I have seen.'

As evident in (38a-b), this prefix expresses both person and number. It also changes form depending on clause type (declarative/interrogative) and tense (present/past). The full paradigms appear in (39) and (40). ${ }^{19}$

\begin{tabular}{|c|c|c|}
\hline & & \\
\hline PRES & SG & $P$ \\
\hline $1 \mathrm{st} / 2 \mathrm{nd}$ & $\varnothing-$ & \\
\hline $3 \mathrm{rd}$ & à- & áa- \\
\hline
\end{tabular}

\begin{tabular}{c|cc} 
PAST & SG & PL \\
\hline 1st/2nd & é- & é-kè- \\
3rd & ée- & áa-kè-
\end{tabular}

\footnotetext{
${ }^{19}$ Note that the plural morpheme $k e ̀$ is an affix, and not a clitic, even though it shows similarities to the 3 rd person plural pronoun. Unlike copied ké, it appears between the clause type/tense prefix and its host. Second, it is restricted to the past tense and so displays tense-variance (Nevins 2011). Finally, unlike copied $k e ́$, it does not alternate between a reduced and full pronominal form.
} 
Interrogative particle:

\begin{tabular}{|c|c|c|c|c|c|}
\hline PRES & SG & PL & PAST & SG & PL \\
\hline $1 \mathrm{st} / 2 \mathrm{nd}$ & & $\varnothing-$ & $1 \mathrm{st} / 2 \mathrm{nd}$ & é- & é-kè- \\
\hline 3rd & $\varnothing-$ & $\varnothing-$ & $3 r d$ & ế- & é-kè- \\
\hline
\end{tabular}

One of the regularities in this paradigm is that, in the past tense, plural is always expressed by the prefix kè, which comes after the past tense prefix. This is the only regular process of inflection marking number, though there are some irregular ways of distinguishing singular and plural, such as the contrast between $\grave{a}$ - and $a ́ a$ - in the declarative present.

The morpheme $k(e)$ also appears in the pronominal paradigm. In free-standing pronouns, plural is marked with a final $-k$, as highlighted in the paradigm for pronouns in the absolutive case in (41). This final consonant stands in opposition to the final $-n$ found with singular pronouns.

Dinka pronouns (absolutive case):

\begin{tabular}{|c|c|c|}
\hline & SG & PL \\
\hline $1 \mathrm{st}$ & 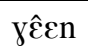 & wôok \\
\hline 2nd & ỵ̂iin & wêe \\
\hline $3 \mathrm{rd}$ & yềen & kêek \\
\hline
\end{tabular}

Although this final $-n$ is regular, it differs from $k(e)$ in that it appears only in this paradigm.

The plural morpheme $k(e)$ also appears with pronominal possessors. In Dinka, possessor enclitics agree in number with the possessum, which is expressed in the initial consonant $(42 \mathrm{a}-\mathrm{b})$.

Possessor clitics agree in number with possessum:

a. kìtâam- $\underline{\text { dù }}$

book.CS-SG.2SG

'your book'

b. kìtèep-kù

books.CS-PL.2SG

'your books'

All possessor clitics take the prefix $d$ - with singular nouns and $k$ - with plural nouns (43).

Pronominal possessor paradigm:

\begin{tabular}{|c|c|c|}
\hline & $\mathrm{SG}$ & PL \\
\hline $1 \mathrm{SG}$ & -diẹ & -ciè \\
\hline $2 \mathrm{SG}$ & -dù & -kù̀ \\
\hline $3 \mathrm{SG}$ & -dè & -kè \\
\hline $1 \mathrm{PL}$ & -dà & -kuà \\
\hline $2 \mathrm{PL}$ & -duọoonn & -ḱkuóonn \\
\hline 3PL & -décn & -ḱḱćn \\
\hline
\end{tabular}


Again, we see that $k(e)$ does work as a regular plural morpheme. The only apparent exception, the 1st person singular enclitic with plural agreement, ciè, is the result of a palatalization rule targeting $k i$ sequences found in the Bor dialect, and the Agar dialect as well (Andersen 2002:17). In other dialects, such as Nyaarweng, this rule is not found and the enclitic is -kiè.

Dinka has a third pronominal paradigm, for subject clitics that attach to the 2nd position verb or auxiliary. These pronominal clitics are used whenever a pronominal subject is not in clause-initial position $(44 a-c)$.

Pronominal non-initial subjects are expressed by clitics:

a. Wôok nhìar pêen.

we love town

'We love the town.'

b. Pêen à-nhiécr Bôl. town 3s-love.ov Bol.GEN

'The town, Bol loves.'

c. Pêen à-nhiárkù. town $3 \mathrm{~S}$-love.1PL The town, we love.'

These clitics affect the second position verb/auxiliary by triggering a number of different allomorphy effects (Andersen 1993). The verb nhićcr in (44b), for example, becomes nhíar in (44c) when followed by the 1 st person plural enclitic -kụ. ${ }^{20}$ Singular clitics are marked solely by such changes to the root. I will not cover this system in detail in here, but see Andersen (1993) for an extensive overview. What it is important for our purposes is that all the plural forms involve an enclitic with an initial $k$-, as illustrated in (45) and (46).

Subject clitic paradigm for câam ('eat'):

\begin{tabular}{c|cc} 
& SG & PL \\
\hline 1st & càam & cám-kù̀ \\
2nd & càm & cám-kè̀ \\
3rd & cècm & cám- $\underline{\text { kè }}$
\end{tabular}

Subject clitic paradigm for gộ?̣r ( 'write'):

\begin{tabular}{|c|c|c|}
\hline & SG & PL \\
\hline $1 \mathrm{st}$ & gàar & gẹ́t-kuụ \\
\hline 2nd & gạ̀r & gẹt-kè \\
\hline $3 \mathrm{rd}$ & gế:̨r & gẹ́t-kè \\
\hline
\end{tabular}

Another set of items with plural and singular inflection is Dinka's enclitic demonstratives. Dinka has a distal and wh-demonstrative, as well as two demonstratives encoding proximity to the speaker or addressee (Andersen 2016:656). Like the possessors, these display number agreement. There is no consistent way of marking sin-

${ }^{20}$ Because of this, I have opted for a simplified monomorphemic gloss throughout (like 'love.1PL' in $(44 b))$. 
gular agreement in these forms, but the plural is always formed by adding an initial $k$-, either directly to the singular base or substituting for the initial consonant (47).

\section{Dinka demonstratives:}

\begin{tabular}{|c|c|c|}
\hline & SG & PL \\
\hline WH & -ò & $-\underline{\mathbf{k}} \mathbf{c}$ \\
\hline PROX.SP & -è & $-\underline{\mathbf{k}}$ \\
\hline PROX.ADDR & -ë & $-\underline{\mathbf{k}}$ \\
\hline DIST & -tùi & $-\underline{\mathbf{k}} \underline{i}$ \\
\hline
\end{tabular}

There is a clear morphological asymmetry then between singular and plural in Dinka. None of the five paradigms described here mark singular in the same way. Not all of them even have regular singular inflection. In contrast, plural consistently uses the same inflection. There is no regular marking for plural in any of these paradigms that does not involve $k(e)$.

It is important to note that, outside of these paradigms, there are instances in which plural is not marked by $k(e)$. In the examples presented above, we can already see this in the present tense paradigm of the declarative particle and in the possessor clitics. The present tense declarative paradigm, for instance, marks the opposition between 3rd person singular and plural by a change in vowel length and in tone (à vs. áa). Similarly, the distinction between singular and plural possessors is marked by unpredictable differences in the vowel and coda (e.g. 3sg -kè vs. 3pl -kécn, in plural nouns). A much bigger pool of variation is found with Dinka nouns, which have been claimed to only have irregular plural marking (Ladd et al. 2009; Andersen 2014). Almost all Dinka nouns pluralize by changes to the root, either in tone, length, voice, or vowel quality. Some example pairs for a number of nouns are given in (48).

Dinka noun pairs:

\begin{tabular}{|c|c|c|}
\hline SG & PL & Meaning \\
\hline nhòm & nhîiiim & 'head' \\
\hline kìtáap & kìtécp & 'book' \\
\hline păal & pěccl & 'knife' \\
\hline riọ̌ou & riọpp & 'nail' \\
\hline čiin & cìn & 'hand' \\
\hline kèrr & kéent & 'shoulder' \\
\hline nyáan & nyiẹ̌ẹ & 'crocodile' \\
\hline
\end{tabular}

In detailed studies of Dinka plurals, Ladd et al. (2009) and Andersen (2014) conclude that the number of a noun cannot be deduced from its phonological form. Whether this conclusion is right does not matter for our purposes, but it could mean that $k(e)$ represents the only regular form of plural inflection in Dinka.

To capture the asymmetry between singular and plural described here, I propose that $k(e)$ is the default spell-out of the feature [plural] in Dinka, unspecified for morphosyntactic context (49). ${ }^{21}$

\footnotetext{
${ }^{21}$ Note that the alternation between $k$ and $k e$ may actually be fully determined by the surrounding syllable structure. The allomorph $k e$ appears in subject enclitics and as part of the declarative/interrogative particles.
} 


$$
\begin{aligned}
& \text { A spell-out rule for plural in Dinka: } \\
& \text { [plural] } \rightarrow k(e)
\end{aligned}
$$

In contrast, we have seen that singular does not have any overt cross-paradigmatic marking and so I suggest that it lacks an elsewhere form. ${ }^{22}$

\subsection{Number in Dinka pronouns}

The singular-plural asymmetry described above mirrors the sensitivity to plural found in ké-copying, in which it is also only plural that is associated with a regular realization. It is this parallel that will motivate my treatment of ké-copying. I will suggest that the rule in (49) allows us to understand what makes the 3rd person plural pronoun $k e ́$ different from all other pronouns.

Let me first be explicit about the syntactic structure I assume for pronouns. In recent work on case and number suppletion, Moskal (2015) and Smith et al. (2016) propose that pronouns contain a functional head encoding person, at their core (PersP here), ${ }^{23}$ below projections encoding number and case (50). ${ }^{24}$

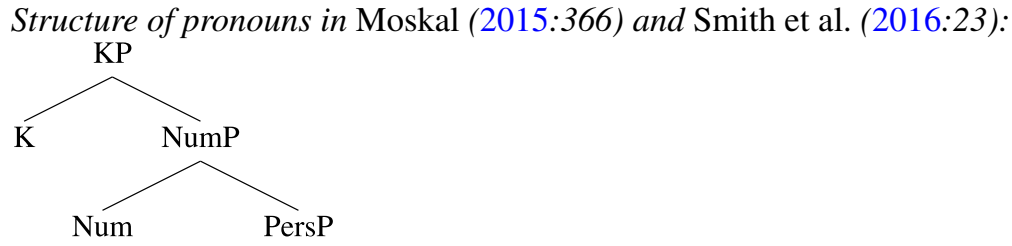

The structure in (50) also fits well with Harbour (2016), whose theory of possible pronoun inventories across languages requires that person be introduced below number.

I adopt the structure in (50), but suggest that the functional head that contributes the person feature is simply a variant of $n$, lacking a root complement:

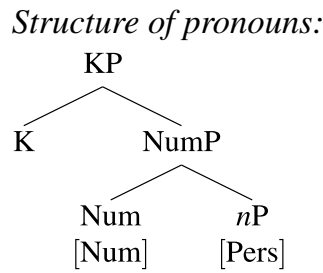

\footnotetext{
The plural enclitics cannot be $k$, because this would create an illegal complex coda (Dinka verbs all end in a single coda consonant). I propose that $k e$ appears in the paradigms for the declarative/interrogative particles because affixes in Dinka do not permit a coda consonant, as previously noted. As a result, the initial $k$ must be the onset, so that the plural morpheme must be a separate syllable.

${ }^{22}$ An alternative would be to say that there is a null elsewhere form for singular. Nothing hinges on this for the proposal I will develop.

${ }^{23}$ See Gruber (2013) for an explicit proposal of what the semantic content of a person phrase at the core of a pronoun might be.

${ }^{24}$ From the perspective of suppletion, what is important about the structure in (50) is that both $\mathrm{K}$ and Num are sufficiently local to the pronoun root to allow pronouns to display suppletion for case and number. In contrast, Moskal proposes that the root of a lexical DPs is below a phasal $n$ and so is too far removed from $\mathrm{K}$ to supplete for case.
} 
I identify Pers as $n$ because it keeps the structure of pronouns and DPs minimally distinct and consonant with the view that pronouns realize DPs without a noun (Postal 1969; Elbourne 2001, 2005). I will also later suggest that the projection that contributes person in pronouns may in some languages be phasal, and identifying it as $n$ allows us to keep the inventory of phase heads restricted. The account I develop is also consistent, however, with a view in which the pronoun root is a functional head unique to pronouns, as long as it has the same phasal properties across languages.

What is crucial for my approach is that these structures put the locus of number above person in pronouns. Another argument for this comes from the observation that, when pronouns can be decomposed into person and number, number affixes appear to come between person and case affixes. ${ }^{25}$ In Turkish, for instance, the plural suffix -lar/-ler is used to form the 3rd person plural pronoun and comes between the suppletive $3 \mathrm{rd}$ person form on and case suffixes (52a). A similar pattern is found in Kayardild (52b).

Number suffixes on pronouns come before case and after person:

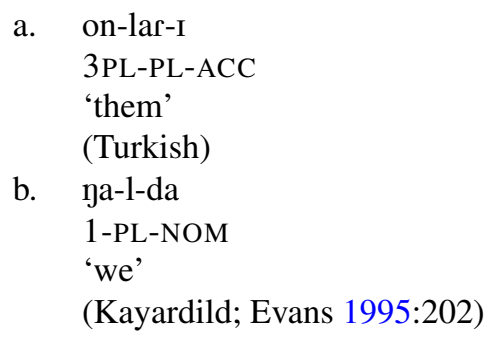

Now that we have motivated a syntactic structure for pronouns, consider again the inventory of Dinka pronouns in (53).

\section{Dinka pronouns (unmarked case):}

\begin{tabular}{c|cc} 
& SG & PL \\
\hline 1st & yêen & wôok \\
2nd & ỵ̣̂in & wêek \\
3rd & yêen & kêek
\end{tabular}

As previously mentioned, all Dinka pronouns consist of two morphemes. At their core is a CV morpheme that expresses both person and number. This morpheme can also appear in isolation and function as the short form of the pronoun, like ké does. In addition, all Dinka pronouns may appear with a final consonant, $-k$ or $-n$, which marks just number.

For all Dinka pronouns except the 3rd person plural pronoun, I propose that the $\mathrm{CV}$ morpheme is the pronoun root, $n$ in the structure adopted above, while the final $\mathrm{C}$

${ }^{25}$ In other words, pronouns appear to obey Greenberg's (1963:95) Universal 39:

Greenberg's Universal 39:

Where morphemes of both number and case are present and both follow or both precede the noun base, the expression of number always comes between the noun base and the expression of case. 
instantiates Num. This view is represented for the 2 nd person pronouns in (54a) and (54b). I assume the spell-out rules in (55), making use of the general form for plural, $k(e)^{26}$

Structure of Dinka 2nd person pronouns:

a.

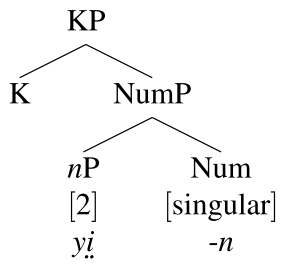

b.

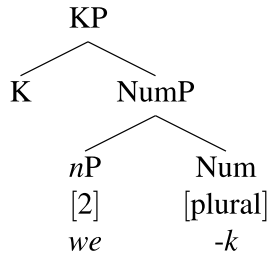

Spell-out rules for Dinka pronouns:

$$
\begin{aligned}
& {[1] \rightarrow y \varepsilon / \ldots \text { [singular] }} \\
& {[1] \rightarrow w o} \\
& {[2] \rightarrow y i l \_ \text {[singular] }} \\
& {[2] \rightarrow \text { we }} \\
& {[3] \rightarrow y e / \ldots \text { [singular] }}
\end{aligned}
$$

$$
\begin{aligned}
& \text { [plural] } \rightarrow-k(e) \\
& \text { [singular] } \rightarrow-n
\end{aligned}
$$

I suggest that the make-up of the 3rd person plural pronoun diverges from $(54 a-b)$, which will ultimately account for the ké-copying effect. Observe that the 3rd plural pronoun is unique in that both the initial $\mathrm{CV}$ and the final $\mathrm{C}$ have the form of Dinka's general plural morpheme $k(e)$. I suggest that this morphological similarity is revealing of a structural difference, namely that the 3rd person plural pronoun expresses only plurality. In this analysis, the 3 rd person plural pronoun is just the general morpheme for plurality, ke, so that there is no overt expression of person in the pronoun at all. I propose that the full form kêek is another allomorph of [plural], used to satisfy the CVVC template for full pronouns. This view treats the alternation between the short and full form of the pronoun as a templatic one, ${ }^{27}$ which aligns well with the observation that there is no apparent syntactic or semantic difference between the two forms, as previously noted in Sect. 2.3. ${ }^{28}$ The $3 \mathrm{rd}$ person plural pronoun is then the product of a set of spell-out rules like (56a), and has the structure in (56b).

\footnotetext{
${ }^{26}$ I omit tones, which I assume come from the spell-out rules for case morphology. It is also possible that the absolutive contour is underlying or default, particularly if unmarked case is taken to reflect the absence of case.

${ }^{27}$ As Andersen (1993) shows, Dinka productively places templatic restrictions of this kind to create morphological alternations. The non-finite form of a transitive verb, for example, is like the full form of the pronoun in that it must have a coda and always lengthens the vowel from the unmarked form.

${ }^{28}$ I assume then that the short and full form of the pronoun are formed from the same syntactic structure. In the short form, the final consonant marking number undergoes deletion in order to fit a $\mathrm{CV}$ template.
} 
Spell-out rules and structure for ké(ek):

a. $\quad[3] \rightarrow \varnothing$

b.

$$
\text { [plural] } \rightarrow-k(e), \text { keek }
$$

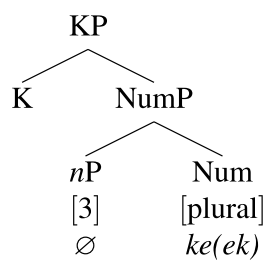

If correct, this approach means that there is an asymmetry in the pronoun inventory between the 3rd person plural pronoun and the other pronouns which mirrors the asymmetry between singular and plural across the language. In the next section, I show that this idea provides an explanation of the number sensitivity of ké-copying, if copied ké realizes only the number part of a copy, through the application of partial deletion.

\section{$4 K e$-copying as partial deletion}

This section develops a partial deletion approach to pronoun copying. We have seen so far that ké-copying provides evidence that there are patterns of multiple copy spellout in which non-clitic pronouns can realize a copy of a full lexical DP. In addition, as we will see in Sect. 5, such constructions are not unique to Dinka. I will now show that an approach to copy deletion based on economy constraints, as in Landau (2006), provides a model of multiple copy spell-out that also predicts pronoun copying, because it forces partial deletion in contexts like ké-copying. If pronouns represent DPs without a noun, as in Postal (1969) and Elbourne (2001, 2005), such an approach predicts pronoun copying. In addition, a partial deletion analysis offers insight into the number asymmetries found in Dinka. If partial deletion removes everything but the NumP and KP layer of a copy, only ké(ek) will be able to surface, under the assumption that only the 3rd person plural pronoun is capable of realizing only number.

\subsection{An economy approach to copy deletion}

Patterns like ké-copying appear to require an analysis in which copy deletion is not tied to linearization conflicts, as in Nunes's $(1995,2004)$ influential approach. This is necessary because the Dinka pronoun copying pattern does not involve cliticization, but rather non-reduced pronouns, which requires that multiple copy spell-out is possible without reducing additional copies to a head. In addition, ké-copying, like other patterns of pronoun copying I will discuss in Sect. 5, involves copies of complex DPs. Instead, I adopt Landau's (2006) proposal that copy deletion is driven by economy constraints at PF. An advantage of this economy approach is that it provides a mechanism by which a copy of a lexical DP is reduced in the context of multiple spell-out, 
by forcing partial deletion in such instances. In this section, I develop this approach and outline the conditions under which it should give rise to pronoun copying.

Landau (2006) develops an algorithm for copy deletion that is driven by economy considerations at PF, specifically a desire to pronounce as little structure as possible. Like Nunes's $(1995,2004)$ approach, this places the burden of copy deletion at PF, but it makes different predictions about multiple copy spell-out. Landau proposes that copy deletion is enforced by two principles, P-Recoverability and Economy of Pronunciation, defined in (57) and (58):

\section{P-Recoverability:}

In a chain $<\mathrm{X}_{1}, \ldots \mathrm{X}_{\mathrm{i}}, \ldots \mathrm{X}_{\mathrm{n}}>$, where some $\mathrm{X}_{\mathrm{k}}$ is associated with phonetic content, $\mathrm{X}_{\mathrm{k}}$ must be pronounced.

(Landau 2006:31)

\section{Economy of Pronunciation:}

Delete all chain copies at PF up to P-recoverability.

(Landau 2006:30)

P-Recoverability ensures that at least one copy of each syntactic object is pronounced, because it requires that all unique phonetic content is realized at least once. ${ }^{29}$ Economy of Pronunciation is an economy principle that maximizes deletion. Taken together, these two principles force deletion of all copies except for one in most instances. In more familiar cases of phrasal movement, like (59a-b), P-Recoverability is satisfied once one copy is fully spelled out. Economy of Pronunciation will then force deletion of all other copies. ${ }^{30}$

Phrasal movement with deletion of all but one copy:

a. Who did you see whe?

b. Kim seems [Kim to be smart].

Importantly, the principle of P-Recoverability also allows for multiple copy spellout, by means of the notion of "association with phonetic content." Landau's definition of this is given in (60).

$\mathrm{X}$ is associated with phonetic content iff:

a. X has phonetic content, or

b. $\mathrm{X}$ is in a position specified with some phonological requirement (Landau 2006:31)

What is crucial here is the clause in (60b). This clause allows for copies that reside in particular syntactic positions to resist deletion even when the phonetic content of $\mathrm{X}$ is already realized elsewhere, as long as that position comes with a unique $\mathrm{PF}$

\footnotetext{
${ }^{29}$ The definition of P-Recoverability means that there must be some way of distinguishing copies from independent reuse of the same lexical item in order to identify whether two phrases are part of the same chain, for example by means of numeration indices (Chomsky 1995).

${ }^{30}$ Importantly, this approach requires that copies of the same item be viewed as syntactic objects that can be manipulated independently, at least at PF. This may be incompatible with some versions of a multidominant approach to movement.
} 
requirement. For example, for the case of Hebrew verb copying he examines, Landau suggests that the lowest copy of the verb must be realized to satisfy the phonological requirement that tense morphology needs to be hosted on the verb, or the Stray Affix Filter. As a result, P-Recoverability is only satisfied if this copy is spelled out rather than deleted. ${ }^{31}$

I propose that the $\mathrm{V} 2$ property of $v / \mathrm{C}$ in $\mathrm{V} 2$ languages may function as a PF requirement in the sense of (60b). I adopt a phonological approach to EPP effects, as in Richards (2001, 2016), Boeckx (2003), and Landau (2007). To be precise, I posit that a feature with an EPP property functions as a spell-out instruction, in the sense of Richards $(2001,2016)$. As a result, phrases that Agree with $v$ for an $\bar{A}$ feature or $\varphi$-features in Dinka are in a position of the type in $(60 \mathrm{~b})$, a position that requires realization. ${ }^{32}$ It will then force multiple copy spell-out under Landau's PRecoverability principle. That the EPP property of a head can force multiple spell-out is also evident in languages like Vata and Nupe, in which movement of a subject requires spell-out of a resumptive pronoun in the gap position (61a-b) (Koopman 1982; Kandybowicz 2007).

Subject extraction in Vata and Nupe requires resumptive pronoun:

a. àló *(ò) lē sảká là?

who he eat rice $\mathrm{WH}$

'Who is eating rice?'

(Vata; Koopman 1982:128)

b. Bagi-zi Musa gàn [CP gànán *(a:) nì enyà] $\mathrm{o}$. man-PL Musa say C 3PL beat drum FOC 'Musa said that THE MEN beat a drum.' 2007:124)

(Nupe; Kandybowicz

One question that arises in this type of approach is why not all EPP positions trigger multiple copy spell-out. This issue is particularly pertinent in Dinka, because there is no comparable ké-copying effect at the $\mathrm{CP}$ edge, even though it also has a V2 effect. I return to this problem in the Sect. 4.4, and suggest that there may be multiple responses to the problem of copy deletion in an EPP position, again drawing on Richards (2001) and Boeckx (2003).

\subsection{Economy of Pronunciation and partial deletion}

I will now show that an economy-based analysis predicts that additional copies in multiple spell-out must be minimal in form, much like a linearization-based approach. In particular, Economy of Pronunciation predicts that, if possible, such secondary copies must undergo partial deletion, because deletion in this instance will not violate P-Recoverability. I argue that this partial deletion operation is what gives rise to pronoun copying across languages.

In Nunes's $(1995,2004)$ model, multiple copy spell-out is possible when a copy undergoes adjunction to another head, allowing it to avoid a linearization conflict.

\footnotetext{
${ }^{31}$ It is also necessary for there to be a phonological requirement associated with the higher copy, because otherwise Economy of Pronunciation will deliver covert movement.

${ }^{32}$ Tying the PF requirement to the EPP property of a feature allows us to explain the observation that $k e$-copying is still necessary when there is a V3 structure at the $v \mathrm{P}$ edge, as in examples like (33).
} 
This works well for cases of verb copying, since the copies involved are all heads. An economy approach deals with such examples in the same way, except it treats the PF requirements that are often associated with head-adjunction to be responsible for spell-out. The two approaches deal differently with instances of multiple copy spell-out that target a multi-word phrase, such as a complex DP. A linearizationbased approach does not allow multiple spell-out in such cases, since phrases cannot undergo head-adjunction. ${ }^{33}$ An economy approach, in contrast, in principle allows multiple spell-out of phrases, as long as each phrase is associated with a unique PF requirement, such as the EPP. However, Economy of Pronunciation does not make the prediction that multiple phrasal copies should be realized intact, because of the possibility of partial deletion. P-Recoverability is satisfied as long as one phrasal copy is faithfully realized, but it allows for some of the material in other phrasal copies to be deleted, as long as a prosodic unit remains that is capable of satisfying the phonological requirement driving multiple copy spell-out. In fact, Economy of Pronuncation should render this obligatory, because it maximizes deletion. In this way, an economy approach allows for multiple copy spell-out with phrasal copies, but limits additional copies to a "minimal" form, or a single prosodic word. ${ }^{34}$ It is this difference between heads and phrases that I will hold responsible for the asymmetry between nouns and verbs that is apparent when we compare most instances of verb copying and pronoun copying: verbs usually copy as verbs, but DPs only copy as pronouns. I suggest that what unifies these is that they represent the most minimal form a verb or DP can take in compliance with Economy of Pronunciation.

With this logic in mind, let us consider how a pronoun could be created from a full phrasal copy of a lexical DP. As in work by Postal (1969) and Elbourne (2001, 2005), I take it that pronouns are the realizations of DPs without a noun complement. This means that the structure I adopt for lexical DPs is in (62). The structure of pronouns I adopted in Sect. 3.3 is in (63).
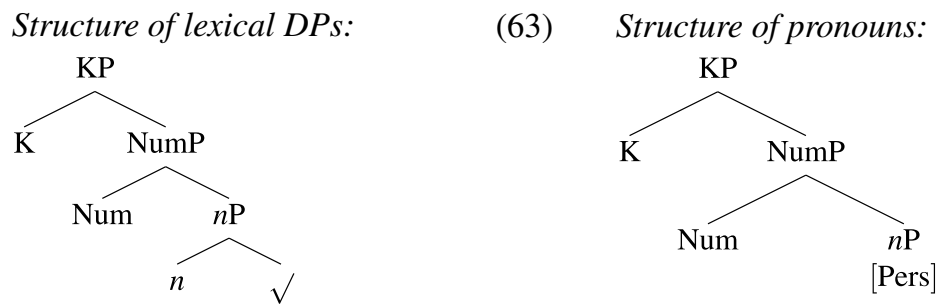

If these structures are correct, then partial deletion of a DP like (62) will always end up with a structure that is fully shared with pronouns. If pronouns represent the morphological realization of functional DP structure in the absence of a noun

\footnotetext{
${ }^{33}$ In principle, a linearization-based approach might be augmented with a partial deletion mechanism and deliver some of the same results (see, for example, Baker and Kramer 2016). Such an approach must still face the issue that there are multiple copy spell-out patterns which do not obviously involve cliticization.

${ }^{34}$ The proposal that copy deletion aims to delete as much as possible seems similar to the idea that ellipsis is constrained by MaxElide (Takahashi and Fox 2005; Merchant 2008; Hartman 2011). If constraints on ellipsis correspond closely to constraints on deletion, as Landau (2006) suggests, Economy of Pronunciation and MaxElide could perhaps be viewed as the same constraint, modulo the role of Parallelism domains.
} 
root (Postal 1969; Elbourne 2001, 2005), this means partial deletion will create a pronoun.

The simplest option is to assume that partial deletion always removes everything but the highest head, K. I will end up pursuing a slightly different proposal, but let me first show how this approach would work. In this view, spell-out of $\mathrm{K}$ is what yields a copied pronoun, with all other material inside the DP copy deleted. In addition, this mechanism delivers pronoun copying without requiring head-adjunction, allowing secondary copies to occupy phrasal positions. A limitation of this approach, however, is that copied pronouns seem to preserve information that is encoded below K. In Dinka, copied ké expresses plurality still, so that we need this information to be present in the copied pronoun also. In fact, all pronoun copying constructions discussed in Sect. 5 preserve number, and some express person as well. As we will see, an apparent generalization across pronoun copying patterns is that number may be preserved without person, while person cannot be preserved without number (64).

\section{Generalization about pronoun copying patterns:}

Copied pronouns that match in person also match in number.

I suggest that the generalization in (64) should derive from the way in which person and number information is organized inside a DP, and specifically from the idea that number is introduced above person (Moskal 2015; Smith et al. 2016; Harbour 2016). A way of doing this is to propose that number and person information may escape deletion through head movement of Num or $n$ up to K. In this view, Num in Dinka would move up to $\mathrm{K}$, so that a copied pronoun always realizes the complex head Num+K. This approach derives the generalization in (64) from the Head Movement Constraint (Travis 1984), since $n$ cannot move up to $\mathrm{K}$ without skipping Num.

A limitation of the approach just outlined is that it requires positing variation in head movement operations across languages that are hard to diagnose on independent grounds. As a result, I will set aside this option here, and explore a different approach, in which partial deletion permits more than just the KP layer to survive. It is important to note, however, that the KP-layer approach outlined above will also capture all of the patterns that I discuss in the rest of the paper (with the possible exception of the pronoun gap discussed in Sect. 5.2).

Another way of allowing number information to survive deletion is to limit partial deletion, so that the NumP layer in fact also survives partial deletion. The idea that Num survives deletion would trivially explain why all pronoun copying constructions discussed in this paper preserve number information. To allow for the NumP layer to escape partial deletion, I propose that partial deletion is not unfettered, but is restricted to phasal domains $(65) .{ }^{35}$ This idea will end up restricting partial deletion in DPs to deletion of $n \mathrm{P}$, allowing number information to remain.

\footnotetext{
${ }^{35}$ This is reminiscent of the idea that ellipsis domains correspond to phasal domains, although it is important here that the phase head is deleted along with the rest of the phase. Alternatively, this could be seen as a constraint on recoverability.
} 


\section{A constraint on copy deletion:}

Only phases undergo deletion.

In other words, I propose that the deletion algorithm involved in the mapping to PF does not delete single heads, but only removes phasal units. ${ }^{36}$

To make the constraint in (65) compatible with deletion of full copies, I adopt the idea that the highest head in an extended projection is always a phase head, as in a dynamic conception of phases (e.g. Bobaljik and Wurmbrand 2005; Bošković 2014). In cases of phrasal movement with a spell-out of a single copy, this assumption means that the effects of (65) are indistinguishable from full copy deletion, because a full copy necessarily corresponds to a phase.

The most important consequence of (65) for present purposes is that it restricts partial deletion. Specifically, (65) predicts that partial deletion is only possible if the copy to be spelled out involves a phasal boundary within it. Let us consider how this applies to a DP copy. I propose that both $\mathrm{K}$ and $n$ are phase heads, so that there are two phases in every lexical DP. ${ }^{37}$ This idea gives us one legitimate option for partial deletion within a DP, namely deletion of $n \mathrm{P}$, which is also a phasal unit. After deletion of $n \mathrm{P}$, the structure that is left behind consists of $\mathrm{K}$, and Num (66).

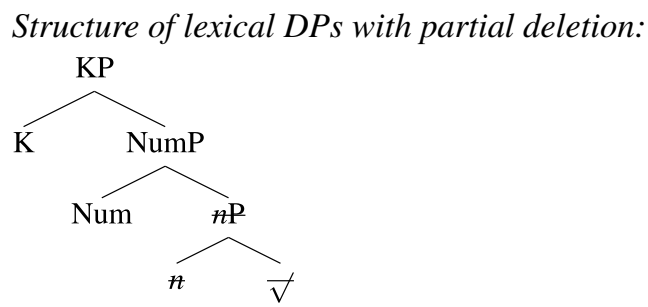

My proposal then is that (66) is always the form of a copy of a lexical DP in the context of multiple copy spell-out. This is the structure I suggest is behind all instances of pronoun copying I discuss in this paper. Importantly, however, (66) is not fully identical to a pronoun, since $n$ is absent. As a result, the structure in (66) can yield pronoun copying, but only if there are pronouns that can realize a structure containing just $\mathrm{K}$ and Num. In other words, (66) requires 3rd person pronouns that are realizations of number, a property that I will suggest varies across and within pronoun inventories. This limiting factor then will be behind the number asymmetries in ké-copying, and also behind variation across pronoun copying patterns.

The structure in (66) will always produce copied pronouns that preserve number and case, which I argue in Sect. 5 is a correct result. However, it allows for a different

\footnotetext{
${ }^{36}$ One possible way of understanding this claim is as the idea that deletion amounts to non-Transfer, if we assume that Transfer applies to an entire phase, as in the linearization-based view of successive cyclicity in Fox and Pesetsky (2005), for example. Equating deletion with non-Transfer does raise questions about the timing of copy deletion, and exactly when Transfer occurs. See also fn. 39.

${ }^{37}$ See Bošković (2015) for a recent defense of the idea that there are two phasal domains in the DP.
} 
result when it comes to person. Specifically, if person is encoded on $n \mathrm{P}$ in pronouns, it will also undergo partial deletion when the input to multiple spell-out is a 1st or 2nd person pronoun. This will produce the person mismatch in Dinka, and in other languages. As we will see in Sect. 5.1, languages vary in this dimension, however. Copied pronouns may also match in person. I will suggest that this is because of a 2nd parameter of variation, whether $n$ is a phase in pronouns. Given the constraint on partial deletion adopted above, this will also lead to variation in pronoun copying.

One question that arises for this $n \mathrm{P}$ deletion view is what happens to dependents of the noun, such as adjectives or possessors. Note, however, that Economy of Pronunciation actually forces deletion of all such phrasal dependents, on the assumption that these are phasal units as well (something which is forced by a dynamic conception of phases).

Before demonstrating how this approach delivers the properties of ké-copying, let me briefly discuss one potentially problematic consequence of the idea that copy deletion is limited to phases. Importantly, this idea is incompatible with traditional head movement, because the copy left by head movement will usually not correspond a phase. As a result, all head movement should result in copying constructions. One aspect of this that is encouraging is that $\overline{\mathrm{A}}$-movement of heads does very frequently lead to multiple copy spell-out. ${ }^{38}$ But something must exempt traditional head movement from the effects of (65). One possibility, which I will adopt here for the sake of clarity, is that such head movement effects are not achieved by syntactic movement, but rather reflect morphophonological operations (e.g. Brody 2000; Hale and Keyser 2002; Harley 2004; Adger 2013; Hall 2015).

The approach to multiple copy spell-out developed here does not build in any fundamental asymmetry between nouns and verbs, except in that movement of a noun by itself is not commonly found. Noun copying should then be possible if a noun moves out a more complex DP by itself. In fact, Trinh (2011) shows that, in Vietnamese, a noun can be topicalized while stranding the rest of the DP, including numerals and classifiers. In such instances, the lower copy of the noun may undergo multiple copy spell-out $(67 \mathrm{a}-\mathrm{b})$.

Noun copying in Vietnamese:

a. ban thi no se gap [DP hai nguoi ban cua John] friend TOP he will meet two CLASS friend of John 'Friend, he will meet two friends of John.'

b. vo thi no se gap [DP hai nguoi vo cua John] wife TOP he will meet two CLASS wife of John 'Wife, he will meet two wives of John.'

(Vietnamese; Trinh 2011:80)

\footnotetext{
${ }^{38}$ This observation led Trinh (2011) to posit a constraint on copy deletion with $\bar{A}$-movement of heads that is very similar to what I suggest here. In particular, Trinh proposes that copies left by head movement can only be deleted in they are final in a phrase (i.e. not followed by an object), based on contrasts between VO/OV languages and differences between transitives and intransitives. For the cases he discusses, we can effectively re-interpret this as the idea that copies of heads can only delete if they are the only element in a phase.
} 
This is evidence that nothing in principle rules out noun copying, and that pronoun copying is a by-product only of multiple spell-out with phrasal movement.

Conversely, if verb copying and pronoun copying arise by the same mechanisms, we should be able to find instances of phrasal movement with verbs that leave a "pronominal" copy, or an auxiliary. Källgren and Prince (1989) show that Swedish VP-fronting fits this description. In Swedish, a verb phrase containing the finite verb can be fronted. In such constructions, the auxiliary göra ('do') must appear in the gap position (68a-b), which cannot occur with the lexical verb without fronting (68c).

Swedish VP-topicalization leaves an auxiliary double:
a. [Läser boken] gör han nu. read.PRES books do.PRES he now 'Reading the book, he is now.'
b. [Läste boken] gjorde han nu. read.PAST books do.PAST he now 'Read the book, he did.'
c. *Han gör läser/läsa boken nu.
he do.PRES read.PRES/read.INF books now
'He is reading the book now.'
(Swedish; Källgren and Prince 1989:47-48)

Importantly, the finite verb and the auxiliary must both express tense morphology. Källgren and Prince defend an analysis exactly analogous to the one proposed here for pronoun copying: the auxiliary acts as a "lexically realized trace" of VP-movement. This is further evidence that the apparent asymmetry between pronoun copying and verb copying is just about the structures of the copies that are left behind by movement and does not reflect an intrinsic difference between verbs and nouns.

Let me now turn to ké-copying, and how this model of pronoun copying derives the number asymmetries that are particular to Dinka. In Sect. 5, I show that these asymmetries have their counterparts in other pronoun copying constructions as well, and demonstrate that variation across pronoun copying patterns can be captured given the parameters of variation I have identified here.

\subsection{Ké-copying as partial deletion}

The economy approach to copy deletion outlined above means that pronoun copying involves partial deletion, specifically of $n \mathrm{P}$. In this section, I show how, given the assumptions about Dinka pronouns defended in Sect. 3.3, this proposal derives the key properties of ké-copying.

I will start with the asymmetry between singular and plural. Consider the derivation of an example with ké-copying. In (69), the plural object mičcr ('giraffes') is topicalized out of the $v \mathrm{P}$, and the intermediate copy in Spec- $\nu \mathrm{P}$ is realized as $k e ́$.

Ké-copying with topicalization of a plural DP:

Miècr áa-càa ké tị̂in.

giraffes 3P-PRF.1SG 3PL see.NF

'The giraffes, I have seen.' 
The derivation of (69) is represented in (70). In the $v \mathrm{P}$ phase, the object miغ̀cr moves to Spec- $v$ P, as a result of an Agree relation with a $\varphi$-probe and $\bar{A}$-probe on $v$, both with an EPP subfeature. The object is subsequently attracted to Spec-CP, by probes on $\mathrm{C}$.

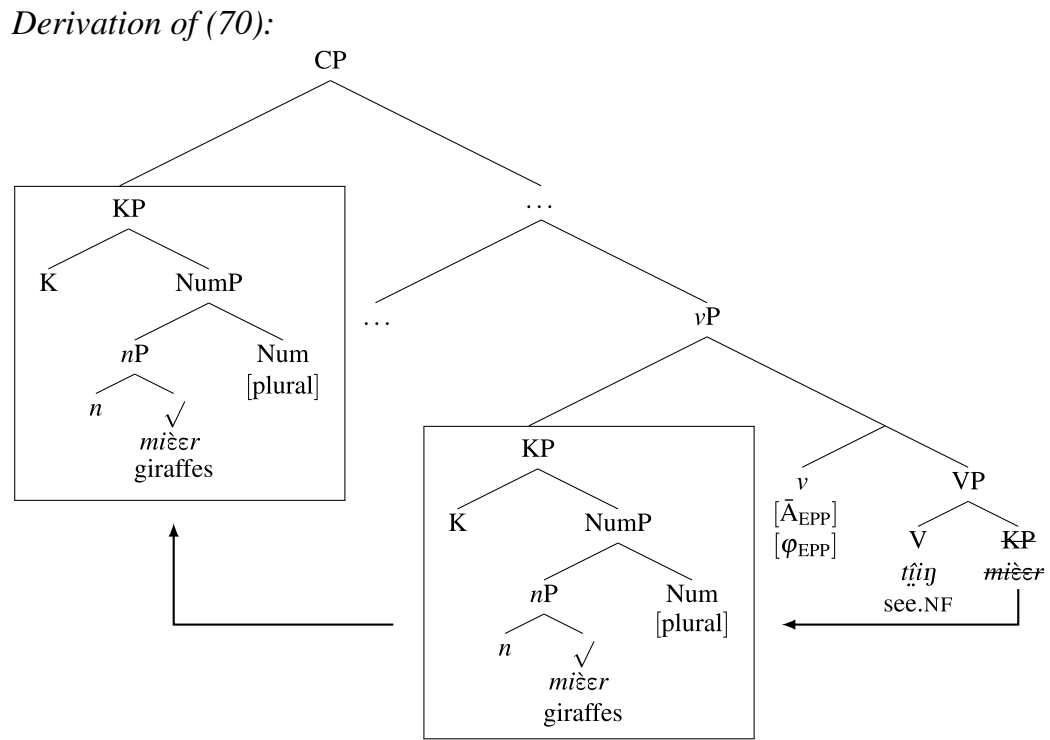

As proposed in the previous section, Economy of Pronunciation and P-Recoverability constrain the mapping to PF. ${ }^{39}$ Let's consider their effects on each copy. No unique $\mathrm{PF}$ requirement is associated with the complement of $\mathrm{V}$ position and its phonetic content is realized elsewhere, and so it undergoes full deletion. However, both the V2 property of $v$, represented by the EPP subfeatures of its probes, and the V2 property of $\mathrm{C}$ function as unique $\mathrm{PF}$ requirements. This means both higher copies must be realized, resulting in multiple copy spell-out. However, as outlined in the previous section, P-Recoverability permits partial deletion of one copy, and so this is forced by Economy of Pronunciation. One KP copy will undergo partial deletion. Since deletion is limited to phases, the only legitimate partial deletion option is to fail to realize the $n \mathrm{P}$ phase within one of the KP copies. As a result, deletion of $n \mathrm{P}$ applies to the copy in Spec- $v \mathrm{P}$, as in (71). Note that nothing guarantees that it is the highest copy, in Spec-CP, which undergoes full spell-out. In fact, I suggest that languages vary parametrically in which copy undergoes partial deletion. As we will see in Sect. 5, there are pronoun copying constructions in which it is the highest copy that is reduced to a pronoun.

\footnotetext{
${ }^{39}$ It is important that copy deletion is ordered before Vocabulary Insertion. This may have consequences for our assumptions about how much structure is visible at PF (e.g. Embick 2010), since it must be the case then that, when copy deletion takes place, at least enough syntactic structure is accessible to evaluate the fate of a copy.
} 


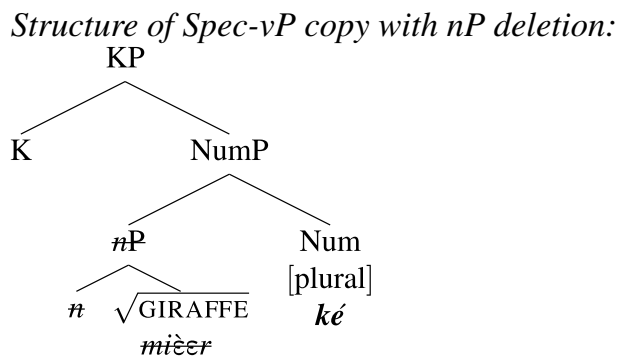

Let us focus now on how the copy in Spec- $v \mathrm{P}$ comes to be realized as a pronoun. The structure that remains after deletion, $\mathrm{K}$ and Num, is shared with pronouns, and looks exactly like the structure I suggested for the 3rd person plural pronouns ké(ek). Importantly, the spell-out rules responsible for the realization of plural in miècr in the usual case are bled by deletion. Since plural marking on nouns is irregular, as described in Sect. 3.2, we can take these insertion rules to look something like (72).

$$
\begin{aligned}
& \text { Insertion rules for number for } \sqrt{\text { GIRAFFE: }} \\
& \sqrt{\text { GIRAFFE }} \rightarrow \text { mičcr } / \\
& \text { [plural] } \rightarrow \varnothing / \sqrt{\text { GIRAFFE }} \text { [plural] }
\end{aligned}
$$

Since the insertion rule for plural requires the presence of the nominal, ${ }^{40}$ it is bled by deletion of $n \mathrm{P}$. As a result, the more general rule for realizing Num in an extended nominal projection applies, the general spell-out rule for plural. The remaining KP and NumP structure is then realized as $k e ́(e k) .{ }^{41}$ This perspective gives us an understanding of why ké-copying does not care about the complexity of the DP antecedent, since all lexical information is deleted in (71). This is why ké-copying behaves the same way regardless of whether the antecedent is itself of a pronoun or a complex DP. All such DPs undergo partial deletion until they contain only a NumP and KP layer. $^{42}$

This proposal also explains the absence of pronoun copying with singular DPs. Suppose the topicalized copy is singular, like the DP mìr ('giraffe'). Partial deletion applies to the copy in Spec- $v \mathrm{P}$ in the same fashion as above, leaving $\mathrm{K}$ and a singular Num, as represented in (73).

\footnotetext{
${ }^{40}$ Note that it must hold in general of the spell-out rules that create morphology specific to nominals that they require the presence of a noun if pronouns are treated as DPs without a noun.

${ }^{41}$ As noted in Sect. 3.3, I assume the same derivation produces the full and the reduced form, the only difference residing in the templatic restrictions placed on the pronoun.

${ }^{42}$ Note that all phrasal dependents of the noun, like higher adjectives, numerals, possessors and perhaps also some quantifiers, must also undergo partial deletion, even if they are attached above the $n \mathrm{P}$ level. This is forced by Economy of Pronunciation, on the assumption that all such phrases are phasal.
} 


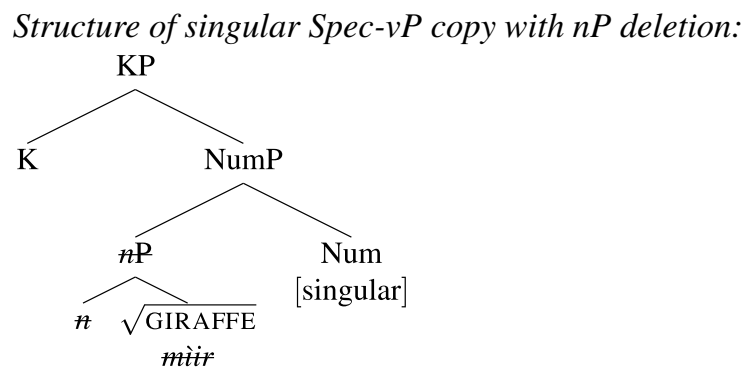

The insertion rules I posited for Dinka pronouns, however, cannot create a pronoun from this structure. The relevant rules are repeated in (74).

$$
\begin{aligned}
& \text { Revelant spell-out rules for 3rd person singular pronoun: } \\
& {[3] \rightarrow \text { ye / _ }[\text { singular] }} \\
& {[\text { singular] } \rightarrow-n / \text { [person] }}
\end{aligned}
$$

Both insertion rules that create the 3rd person singular pronoun yêen make explicit reference to person. Because there is no projection that encodes person in (73), no pronoun can be created from this structure. There is no general (overt) spell-out for singular in Dinka in the way that there is for plural and so the structure in (73) can only receive a null spell-out. It is important here that the copy deletion rules are myopic in a specific way. In order for gaps in pronoun copying to be admissible, it is crucial that the attempt to spell out the structure in (73) still satisfies P-Recoverability, even though no overt form results. In other words, P-Recoverability must require only that Vocabulary Insertion rules apply, but has to be blind to the actual outcome. See Richards (2016) for a similar kind of blindness in the mapping from syntax-to-PF. There are also a number of assumptions in the logic of how Vocabulary Insertion works in the above that are worth discussing in more detail. A syntactic node must be able to fail to receive a spell-out without inducing ungrammaticality. ${ }^{43}$ In addition, structures removed by copy deletion must no longer count for insertion rules, so that the deletion of $n \mathrm{P}$ structure (and the associated [person] feature) bleeds the application of the [singular] rule in (74). ${ }^{44}$

Let me now turn to the absence of person features on copied ké, as in examples like (75). An $n \mathrm{P}$ deletion approach also explains why copied ké does not match its antecedent in person.

No person features on copied ké:

Wêek cịi Áyèn [ ${ }_{\nu \mathrm{P}}$ ké tị̂in].
2PL PRF.OV Ayen.GEN
'You all, Ayen has seen.'

\footnotetext{
${ }^{43}$ Another theoretical option, however, is to say that the null spell-out represents the elsewhere form.

${ }^{44}$ An alternative analytical option could be to say that the rule does apply, yielding the affix $-n$, but that this affix undergoes subsequent deletion, because it is stranded. In this view, what would distinguish the plural is only that a well-formed pronoun can be created from just the Number head.
} 
As suggested in Sect. 3.3, the structure of a copy of the 2nd person plural pronoun is in (76). I propose that the projection that contributes the person root, $n \mathrm{P}$, is phasal, so that it undergoes partial deletion also.

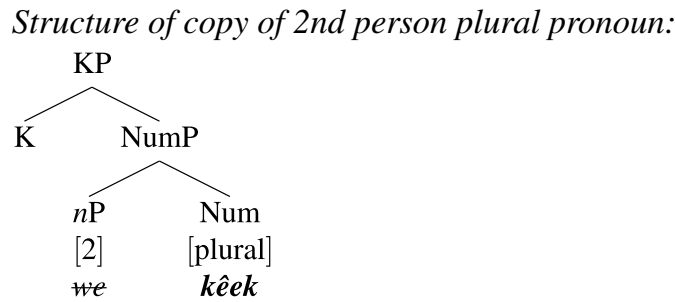

The resulting structure is again identical to the structure of a 3rd person plural pronoun and so surfaces as ké(ek), just as with lexical DPs. Since person is contributed by $n$, it is absent on the copied pronoun. Unlike with lexical DPs, I propose that whether $n$ is a phase in pronouns varies across languages. In Dinka, $n$ is always a phase, but I will argue that, in other languages, the phasal status of $n$ varies according to whether it takes a root complement. In languages in which $n$ is not phasal in pronouns, copied pronouns will match in person as well as number. I examine this dimension of variation in detail in Sect. 5.1, where I also suggest an independent diagnostic for the phasehood of $n$ in pronouns.

To recap this section, we have seen that analyzing ké-copying as partial deletion explains both the gap with singulars as well as the person mismatch with pronouns. Both follow from the logic of partial deletion. The gap with singulars arises because partial deletion removes too much structure for a pronoun to be created from the remaining parts. The person mismatch results because deletion removes the $n \mathrm{P}$ projection that encodes person features. In the rest of the paper, I show that this model provides a unified account of pronoun copying constructions, including resumption, wh-copying, and subject doubling, and can account for variation across these constructions.

\subsection{On the absence of copying at Spec-CP}

Before moving on to a discussion of pronoun copying across languages, let me examine why pronoun copying is absent at the $\mathrm{CP}$ edge in Dinka. One question that arises from the perspective of successive cyclicity is whether we should expect to find languages in which there is pronoun copying both at the $\mathrm{CP}$ edge and the $v \mathrm{P}$ edge. This issue is particularly relevant for Dinka, in which $\mathrm{CP}$ and $v \mathrm{P}$ show highly parallel behavior. Just as I described for the $v \mathrm{P}$ in Sect. 2.1, intermediate movement to the CP edge satisfies V2 there (see Van Urk and Richards 2015). If the $\mathrm{V} 2$ property of $v$ is responsible for ké-copying, the $\mathrm{V} 2$ property of $\mathrm{C}$ might be expected to have the same effect. However, ké-copying in Spec-CP is ungrammatical (77). ${ }^{45}$

\footnotetext{
${ }^{45}$ Note that V2 in embedded clauses may be accompanied by some complementizers. I assume that Dinka has an articulated C domain, in which V2 is established at the lowest head. See Van Urk (2015) for more discussion.
} 
No ké-copying at Spec-CP:

Yè k̂oc-kò [CP yụ̀ụù̀ ké luêeel [CP ẹ̀ (*ké) càm cuị̂in]]?

be.3SG people-which be.1PL 3PL say.NF C 3PL eat food

'Which people do we say are eating food?'

This fact is surprising if we adopt a phonological approach to the EPP, so that the EPP property of a feature functions as a spell-out instruction (e.g. Richards 2001, 2016; Boeckx 2003; Landau 2007). The V2 requirement of $C$ should function as a unique $\mathrm{PF}$ requirement from the perspective of P-Recoverability, just like the V2 property of $v$. Richards (2001) and Boeckx (2003) point out, however, that languages may adopt several strategies to facilitate copy deletion in an EPP position. One is multiple copy spell-out. Another is the phenomenon of anti-agreement, in which agreement triggered in the EPP position is either deleted or impoverished in the context of extraction. I will now show that we can tie the absence of ké-copying at $\mathrm{C}$ to an anti-agreement effect.

Although $\mathrm{C}$ and $v$ both have the V2 property in Dinka, an independent difference between the two is that $\mathrm{C}$ hosts agreement in person and number with the nominal that moves through its edge, on a prefix called the declarative/interrogative particle (see also Sect. 3.2). Interestingly, although this prefix usually expresses both the person and number feature of the DP in Spec-CP, in the context of extraction an antiagreement effect obtains. As evident in the examples of long-distance relativization and topicalization in (78a-b), intermediate $\mathrm{C}$ only shows agreement in number and not in person (see also the paradigms in Sect. 3.2).

$\varphi$-agreement at $C$ with terminal and intermediate movement:

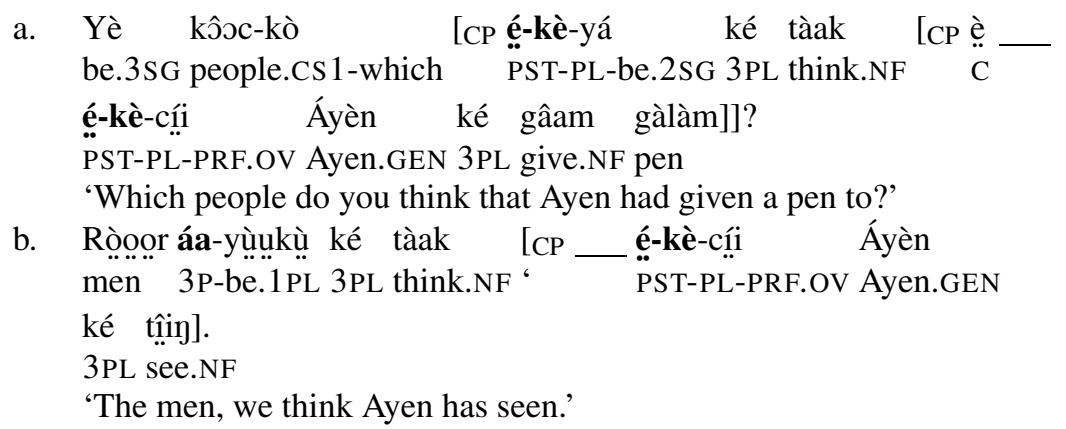

The presence of this anti-agreement effect is an independent difference between the edge of the clause and the edge of the verb phrase, where no overt agreement is ever found. Following Richards (2001), I suggest that anti-agreement is one way to resolve the problem posed by movement out of an EPP position, by deleting the features that require spell-out. Concretely, I propose that Impoverishment rules may delete the feature that requires spell-out, along with its EPP subfeature, at PF (see Baier 2016). ${ }^{46}$ If Impoverishment applies before copy deletion, then anti-agreement

\footnotetext{
${ }^{46}$ This idea also allows us to accommodate speakers for whom ké-copying is optional. We can assume that these speakers extend the Impoverishment rule to include $v$, even in the absence of overt evidence for anti-agreement. Alternatively, there may just be differences in their representation of the pronoun ké(ek).
} 
can pre-empt multiple copy spell-out in this fashion. In support of this, note that Nupe and Vata, languages in which an overt pronoun must accompany subject extraction, both lack subject-verb agreement. This makes sense if pronoun copying is necessary when an anti-agreement effect does not obtain.

The above discussion suggests that there are likely Dinka-internal reasons why $k e$-copying is only necessary at the $v \mathrm{P}$ edge. However, it is worth noting that we have not seen any reason to think it is not possible for a language to display multiple copy spell-out at both the $\mathrm{CP}$ and $v \mathrm{P}$ edge. At the same time, in the model of multiple copy spell-out advocated here, we can see why such a system would be rare. Such a system is only possible if both the $\mathrm{CP}$ and $\nu \mathrm{P}$ edge display something like the EPP property, and such languages are not at all common. It should be clear, for instance, that we do not expect to find pronoun copying at the edge of the verb phrase in a $w h$-copying language like German: it lacks an obvious EPP position at the $v \mathrm{P}$ edge.

\section{Person mismatches and gaps in pronoun copying}

In this section, I show that the approach to pronoun copying outlined in Sect. 4.1 offers a unified account of pronoun copying constructions. In particular, we will see that similar effects to the featural mismatch and the singular gap found in Dinka are attested in other constructions in which pronouns have been analyzed as realizations of the gap, such as resumption, wh-copying, subject doubling, and clitic doubling (e.g. Zaenen et al. 1981; Koopman 1982, 1984; Sells 1984; Engdahl 1985; Pesetsky 1998; Kandybowicz 2007; Holmberg and Nikanne 2008; Harizanov 2014; Sichel 2014). I demonstrate that we can capture these person mismatches and gaps in the same way and show how a partial deletion model can accommodate variation across pronoun copying constructions.

\subsection{Person mismatches}

One of the surprising aspects of Dinka ké-copying is that the copied pronoun only matches the antecedent DP in number features and not in person, which I derived from $n \mathrm{P}$ deletion. This person mismatch effect is not limited to Dinka, but is in fact more commonly found in pronoun copying constructions. In addition, there are languages in which the copied pronoun does realize person in addition to number. I propose that we can capture this variation if $n$ in some languages is not a phase in pronouns.

Kandybowicz (2007) documents a person mismatch effect in Nupe resumption. In Nupe, long-distance subject extraction must leave behind a resumptive pronoun in the lower subject position (79).

Nupe long-distance subject extraction requires resumptive:

Bagi-zi Musa gàn [CP gànán *(a:) nì enyà] o.

man-PL Musa say C 3PL beat drum FOC

'Musa said that THE MEN beat a drum.'

(Nupe; Kandybowicz 2007:124) 
As in Vata (Koopman 1982; Koopman and Sportiche 1986), this type of resumption patterns like movement. It is island-sensitive, for example, and so is impossible out of a $w h$-island (80a), or a subject island (80b).

Nupe resumption is island-sensitive:

a. *Zě Musa kpe [CP ké u: si] o. who Musa know what 3SG buy FOC 'Who does Musa know what bought?'

b. *Etsu [CP gànán u: doko] tán Musa o. chief C 3SG buy horse pain Musa FOC 'That THE CHIEF bought a horse pained Musa.' (Nupe; Kandybowicz 2007:132)

Importantly, as Kandybowicz points out, the Nupe resumptive pronoun is also insensitive to the person features of pronominal antecedents. Movement of a 1 st or 2nd person singular pronominal subject must use the 3rd person singular resumptive $(81 \mathrm{a}-\mathrm{b})$ :

1st/2nd person singular subjects resumed by 3rd person singular:

a. Mi Musa gàn [CP gànán u:/*mi: pa eci] o. 1SG Musa say C 3SG/1sG pound yam FOC 'Musa said that I pounded a yam.'

b. Wo: Musa gàn [CP gànán u:/*wo: pa eci] o. 2SG Musa say C $3 \mathrm{SG} / 2 \mathrm{SG}$ pound yam FOC 'Musa said that YOU pounded a yam.' (Nupe; Kandybowicz 2007:134)

At the same time, the copied pronoun does match the antecedent in number. 1st and 2nd person plural pronouns are necessarily resumed by the 3rd person plural ( $82 \mathrm{a}-\mathrm{b})$.

\section{1st/2nd person plural subjects resumed by 3 rd person plural:}

a. Yi: Musa gàn [CP gànán a:/*yi:/*u: pa eci] $\mathrm{o}$. $1 \mathrm{PL}$ Musa say C 3PL/1PL/3SG pound yam FOC 'Musa said that WE pounded a yam.'

b. Ye: Musa gàn [CP gànán a:/*wo:/*u: pa eci] 0. 2PL Musa say C $3 \mathrm{PL} / 2 \mathrm{PL} / 3 \mathrm{SG}$ pound yam FOC 'Musa said that YOU ALL pounded a yam.'

(Nupe; Kandybowicz 2007:134)

As in Dinka then, the copied pronoun has to match the antecedent DP in number features, but surfaces with a default person value when realizing a copy of a pronoun. Note that the absence of pronoun copying with singulars is not found in Nupe. In Nupe, singular number is still matched on a 3rd person singular pronoun.

The Nupe facts demonstrate that the number matching pattern is not limited to intermediate copying. We also find this pattern when the pronoun is the realization of the highest copy. Colloquial Finnish allows a subject to be doubled by a clause-initial pronoun (83a-b). Holmberg and Nikanne (2008) analyze this 
as multiple copy spell-out, because the pronoun may express the case features of the antecedent and behaves like a phrasal DP in terms of its syntactic positioning.

Initial pronoun may double subject in Finnish:

a. Se on Jari lopettanut tupakoinnin.

3SG has Jari quit smoking

'Jari has quit smoking.'

b. Ne sai kaikki lapset samat oireet.

3PL got all children same symptoms

'All the children got the same symptoms.'

(Finnish; Holmberg and Nikanne 2008:326)

As Holmberg and Nikanne point out, the doubled subject need not match in person. Instead, the 3rd person singular may be used to double 1st and 2nd person singular pronouns $(84 \mathrm{a}-\mathrm{b})$, and, for some speakers, the 3rd person plural pronoun can be used to double 1 st and 2 nd person plural pronouns $(84 \mathrm{c}-\mathrm{d})$.

(84) Finnish subject doubling can be person-insensitive:

a. Se ole-n minä-kin lopettanut tupakoinnin.

3SG are-1SG 1SG-too quit smoking

'I have quit smoking, too.'

b. Se ole-t sinä-kin lopettanut tupakoinnin.

3SG are-2SG 2SG-too quit smoking

'You have quit smoking, too.'

c. Ne ollaan me-kin lopettanut tupakoinnin.

3PL are.1PL 1 PL-too quit smoking

'We have quit smoking, too.'

d. Ne ollette te-kin lopettanut tupakoinnin.

3PL are.2PL 2PL-too quit smoking

'You all have quit smoking, too.'

(Finnish; Holmberg and Nikanne 2008:327,328)

Unlike in Dinka or Nupe, this is not obligatory. For all speakers, 1st and 2nd person pronouns may be doubled by an identical initial pronoun as well, as the examples in (85a-b) evidence.

Finnish subject doubling may match in person:

a. Me ollaan me-kin lopettanut tupakoinnin.

1PL are.1PL 1 PL-too quit smoking

'We have quit smoking, too.'

b. Te ollette te-kin lopettanut tupakoinnin.

2PL are.2PL 2PL-too quit smoking

'You all have quit smoking, too.'

(Finnish; Holmberg and Nikanne 2008:328)

Importantly, there is an asymmetry here between person and number. Although mismatches in person are tolerated, matching in number is obligatory. The third per- 
son singular, for instance, cannot be used to double any of the plurals, as the examples in $(86 a-b)$ show. Similarly, the 1 st and 2 nd person singular pronouns cannot double their respective plurals $(86 \mathrm{c}-\mathrm{d})$.

(86) Finnish subject doubling is never number-insensitive:

a. *Se ollaan me-kin lopettanut tupakoinnin.

3SG are.1PL 1PL-too quit smoking

'We have quit smoking, too.'

b. *Se ollette te-kin lopettanut tupakoinnin.

3SG are.2PL 2PL-too quit smoking

'You all have quit smoking, too.'

c. *Minä ollaan me-kin lopettanut tupakoinnin.

1SG are.1PL 1 PL-too quit smoking

'We have quit smoking too.'

d. *Sinä ollette te-kin lopettanut tupakoinnin.

2SG are.2PL 2PL-too quit smoking

'We have quit smoking too.'

(Finnish; Holmberg and Nikanne 2008:328, Urpo Nikanne, p.c.)

That this pattern of person-insensitivity shows up in a wide range of pronoun copying constructions provides evidence that these constructions should be given a unified treatment. The similarities between Finnish, Nupe, and Dinka are striking, given the very different functions that pronoun copying fulfils in all of these languages. In the pronoun copying approach developed above, we can extend the same treatment to these languages. The copied pronoun is a product of $n \mathrm{P}$ deletion, which deletes person, and not number. Although not necessarily as morphologically obvious as in Dinka, I propose then that 3rd person pronouns in these languages all have the structure of Dinka ké(ek): they realize only number. In Nupe and Finnish, this is true of the 3rd person singular pronouns as well, so that they lack the singular gap. In other words, I posit that Nupe $u$ : and Finnish se have the structure in (87).

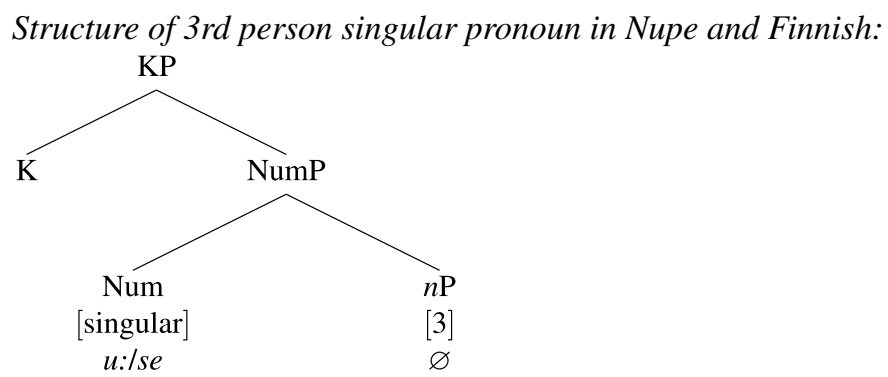

As a result, pronoun copying will always deliver an overt result, unlike in Dinka, but never one that matches in person.

A question that arises now is how to accommodate those Finnish speakers which allow full matching, for person and number. Let me point out first that this pattern is more widely attested. Another pronoun copying construction with full matching 
in resumption is Yoruba. Yoruba, like Vata and Nupe, requires a resumptive pronoun when a subject undergoes movement. Unlike in Nupe, this resumptive pronoun must spell out all of the features of a pronoun it is copying. As (88a-d) demonstrate, the resumptive pronoun matches in both person and number if a pronoun is moved. ${ }^{47}$

Yoruba resumptive subjects match in $\varphi$-features:

a. Èmi ni [CP mo ra àpò].

$1 \mathrm{SG}$ be $1 \mathrm{SG}$ buy bag

'I was the one who bought a bag.'

b. Àwa ni [CP a ra àpò].

$1 \mathrm{PL}$ be 1PL buy bag

'We were the people who bought a bag.'

c. İwo ni [CP o ra àpò].

2SG be 2SG buy bag

'You were the one who bought a bag.'

d. Eyin ni [CP e ra àpò].

2PL be 2PL buy bag

'You are the people who bought a bag.'

(Yoruba; Adesola 2010:82)

This pattern is then minimally different from the Nupe one, but with matching in person also.

There is similar variation in pronoun spell-out of intermediate copies. We can compare Dinka to Seereer, which displays a strikingly similar pronoun copying pattern at the CP edge (Baier 2014). In Seereer, copied pronouns accompany movement across a clause boundary. Copied pronouns appear immediately after the complementizer $(89 \mathrm{a}-\mathrm{b})$.

Pronoun copying in Seereer:

a. Xar foog-o [CP yee ten Yande a-lay-u [CP yee ten

what think-2SG.EXT C 3SG Yande 3-say-EXT C 3SG

Jegaan a-ga'-u]]?

Jegaan 3-see-EXT

'What do you think Yande said Jegaan saw?'

b. Aniin foog-o [CP yee den Yande a-lay-u [CP yee den who.PL think-2SG.EXT C 3PL Yande 3-say-EXT C 3PL

Jegaan a-ga'-u]]?

Jegaan 3-see-EXT

'Who all do you think Yande said Jegaan saw?'

(Seereer; Baier 2014)

Pronoun copying in Seereer targets a different domain edge (the edge of CP) and does not show a gap, as the examples above attest. Seereer pronoun copying is similar to

${ }^{47}$ Adesola observes that it is also possible to leave an expletive in the subject position, which, in Yoruba, is the 3rd person singular pronoun. This could also be analyzed as a "bare resumptive" in the sense of Adger (2011). 
$k e$-copying in many respects, however. Like ké-copying, it is an obligatory reflex of long-distance movement. In addition, as Baier shows, Seereer pronoun copying is movement-derived. Movement with copied pronouns is island-sensitive and so cannot cross a $w h$-island, for example (90).

(90) Seereer pronoun copying is island-sensitive:

*Xar and-o [CP ndax ten Ami a-ga'-u _ ]
what know-2SG.FOC C.INT 3SG Ami 3-see-FOC
'What do you know whether Ami saw __?'
(Seereer; Baier 2014)

As in Dinka, movement with pronoun copying may reconstruct. The examples in (91a-b) illustrate that these dependencies may reconstruct for long-distance (91a), and intermediate binding (91b).

Seereer pronoun copying shows reconstruction:

a. [DP $\left.\mathbf{x o o x} \mathbf{u m}_{\mathbf{i}}\right]$ pro a-nqalaat-u [CP yee ten Yande $\mathrm{i}_{\mathrm{i}} \mathrm{a}-\mathrm{ga}$ - $\mathrm{u}$ REFL 3SG 3PL 3-think.PL-FOC C 3SG Yande 3-see-FOC ].

'It's herself $f_{i}$ that they think Yande $_{i}$ saw

b. [DP $\mathbf{x o o x}$ den $\left._{\mathbf{i}}\right]$ pro $_{\mathrm{i}}$ a-nqalaat-u [CP yee ten Yande a-ga'-u REFL 3PL 3PL 3-think.PL-FOC C 3SG Yande 3-see-FOC ].

'It's themselves ${ }_{i}$ that they $y_{i}$ think Yande saw

(Seereer; Baier 2014)

Unlike in Dinka, copied pronouns in Seereer match fully, so that 1st and 2nd person pronouns are doubled by identical pronouns, as in (92), for example.

Pronoun copying matches in person in Seereer:

Mi foog-o [CP yee mi/*ten ret-u Dakar].

1SG think-2SG.EXT C 1SG/3SG go-FOC Dakar

'It's me who you think went to Dakar.'

(Seereer; Baier 2014)

In all copying configurations then, we find languages with matching for number only and languages with full matching. To understand this variation in pronoun copying patterns, I propose that languages may vary as to whether the $n$ head found at the core of a pronoun is a phase head, like its counterpart in lexical DPs. In languages in which a copied pronoun matches in person, the intransitive version of $n$ found in pronouns is not phasal. This means that languages fall in two categories. In languages like Dinka, Nupe, and Finnish, pronouns contain two phasal boundaries (93). But, in Seereer and Yoruba, pronouns just have one phasal boundary, KP (94). 


\section{Pronouns in person}

mismatch languages:

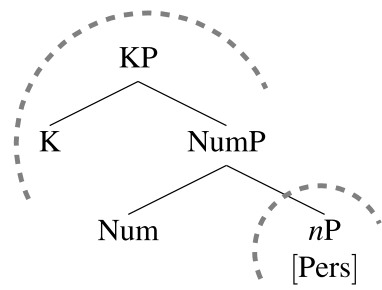

(94)

\section{Pronouns in full matching}

languages:

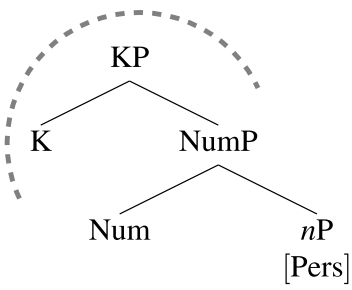

If $n \mathrm{P}$ is not a phasal unit in a pronoun, as in (94), then multiple copy spell-out of a pronoun will not allow any partial deletion, as per the logic of deletion outlined in Sect. 4.1. As a result, a fully matching copy must surface. Since $n$ is still a phase in lexical DPs, no differences should be found there. This approach also straightforwardly derives the absence of pronoun copying that matches only in person. As long as person is always below number, partial deletion does not yield this option. Although Economy of Pronunciation guarantees one outcome at PF, we can model variation within the grammar of a single speaker in this dimension as well, such as the optional number mismatches allowed by Finnish speakers. Speakers that allow an optional mismatch would vary in whether $n$ is a phase head (resulting in number matching) or not (resulting in full matching).

One question is whether we can find independent differences between pronouns across languages that support the phasal distinction I posit in (94). Suppletion patterns might provide one such diagnostic. Moskal (2015) shows that pronouns and nouns differ crosslinguistically in the suppletion patterns they allow. Pronouns commonly supplete both for plural and case. Nouns, however, supplete only for number for the most part. In Dinka, for example, the plurals for mòc ('man') and tìik ('woman') are suppletive (95).

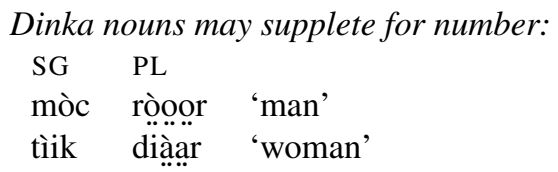

Moskal (2015) presents an account of this difference between pronouns and lexical DPs that makes crucial use of the idea that the $n \mathrm{P}$ phase is missing in pronouns. To be precise, she proposes that, because $n$ is a phase head, case features end up not sufficiently local to a noun root to trigger suppletion (see also Embick 2010; Bobaljik 2012).

However, in Smith et al.'s (2016) survey of suppletion patterns, pronouns fail to supplete for case in 76 out of 160 languages in their sample (47.5\%). Suppose then that these are languages in which $n$ does project a phase boundary, so that pronouns behave like nouns with regard to suppletion. This makes the prediction that languages with number matching only should not show suppletion for case, which seems to be borne out at least in the sample of languages considered here. In Dinka, pronouns 
only supplete for number and, like other nouns, mark case only by differences in tonal contour. Nupe lacks case marking and so vacuously satisfies this prediction. Finnish is also compatible with this prediction, because its pronouns are non-suppletive, as evident in the paradigms for 1 st and 2 nd person pronouns given in (96).

Finnish pronouns do not supplete for case:

\begin{tabular}{l|ll} 
& $1 \mathrm{SG}$ & $2 \mathrm{sG}$ \\
\hline NOM & minä & sinä \\
GEN & minu-n & sinu-n \\
ACC & minu-t & sinu-t \\
PART & minu-a & sinu-a \\
ADESS & minu-lla & sinu-lla \\
ILLAT & minu-un & sinu-un
\end{tabular}

(Karlsson 2015:Sect. 13.2)

Although the languages with full matching discussed here (Seereer and Yoruba) lack case, suppletion could then potentially serve as an independent diagnostic for the phasal distinction proposed above.

\subsection{Gaps in pronoun copying}

Having established that there is a person-number asymmetry in the behavior of pronoun copying across languages, I now turn to the second asymmetry evident in pronoun copying in Dinka, the gap with singulars. In this section, I point out two comparable gaps in other pronoun copying constructions, in which a subset of antecedent DPs fail to trigger pronoun copying. I show that these gaps too follow from the idea that partial deletion may delete too much of a DP copy, so that no copied pronoun can be created.

Another gap sensitive to the $\varphi$-features of the antecedent DP is found in German wh-copying, as described by Pankau (2013). Pankau (2013:ch. 3) shows that whcopying in German requires matching both in case and $\varphi$-features. Copied $w h$-phrases always carry the same case as the full DP $(97 a-c)$.

Wh-copying involves case matching:

a. Wem glaubst du [CP wem deine Eltern __ vertrauen]? who.DAT believe you who.DAT your parents trust 'Who do you think your parents trust?'

b. Wen glaubst du [CP wen deine Eltern _ gesehen who.ACC believe you who.ACC your parents seen haben]?

have

'Who do you think your parents saw?'

c. Wer glaubst du [CP wer ihn getötet hat]? who.NOM believe you who.NOM him killed has 'Who do you think killed him?'

(German; Pankau 2013:177) 
Whether wh-copying involves matching in $\varphi$-features also is harder to investigate, because $w h$-pronominals are necessarily 3rd person and, as Pankau points out, only have a masculine and a neuter form in German. The paradigm for German whpronouns is given in (98).

\begin{tabular}{c|ccc|c}
\multicolumn{6}{c}{ German wh-pronouns (Pankau 2013:60): } \\
& MASC & FEM & NEUT & \\
\hline NOM & wer & - & was & - \\
ACC & wen & - & was & - \\
DAT & wem & - & was & -
\end{tabular}

Using this paradigm, all we appear to be able to determine is that a copied whpronoun must match a higher masculine wh-phrase in gender, as in (99).

Copied wh-pronoun matches in gender:

a. *Wen glaubst du [CP was sie gesehen hat]? who believe you what she seen has 'Who do you think she has seen?'

b. Wen glaubst du [CP wen sie __ gesehen hat]? who believe you who she seen has 'Who do you think she has seen?'

(German; Pankau 2013:59)

However, as Pankau shows, an interesting pattern emerges with complex whphrases, for speakers that allow copying. A conflict arises with complex $w h$-phrases that are feminine or plural. The copied $w h$-pronoun should agree in gender and number, but there is no agreeing pronoun in (98). The result is that wh-copying is obligatorily absent, as the examples in (100a-b) attest for extraction of a singular feminine.

(100) Feminine complex wh-phrase prohibits wh-copying:

a. *Welche Frau glaubst du [CP wen er eingeladen
which woman believe you who.MASC.ACC he hat]?

has

'Which woman do you think he has invited?'

b. *Welche Frau glaubst du [CP was er __ eingeladen which woman believe you who.NEUT.ACC he invited hat]?

has

'Which woman do you think he has invited?'

(German; Pankau 2013:63)

Instead, only regular long $w h$-movement is possible. These facts suggest that whcopying must involve matching in gender and plural, in addition to case, and that 
a gap arises as a result, just as in Dinka ké-copying. ${ }^{48}$ We can understand this gap if wer and was are not default forms, but are specified for masculine and neuter, respectively. ${ }^{49}$ If correct, then $n \mathrm{P}$ deletion would not leave a structure that can spell out a $w h$-pronominal, since there is no $w h$-pronoun form with the correct gender or plural features, leading to an absence of wh-copying. ${ }^{50}$

There is another gap that often appears in pronoun copying, commonly attested in $w h$-copying constructions. Many researchers working on $w h$-copying have noted that, for many speakers, wh-copying is limited to $w$ h-pronominals (e.g. Fanselow and Mahajan 2000:220-221; Felser 2004:550; Pankau 2013:46-47). Such speakers allow (101a), but disallow copying with complex $w h$-phrases (101b-c).

Some speakers only tolerate copying with pronouns:

a. Wen glaubst du [CP wen sie_liebt]? who believe.2sG you who she loves 'Which man do you think she loves?'

b. *Welchen Mann glaubst du [CP wen sie __ eingeladen hat]? which man believe.2sG you who she invited had 'Which man do you think she has invited?'

c. Welchen Mann glaubst du [CP dass sie __ eingeladen hat]? which man believe.2sG you that she invited had 'Which man do you think she has invited?'

(German; Pankau 2013:1,47)

Van Craenenbroeck and Van Koppen (2002) show that similar variation exists across dialects of Dutch with regard to subject doubling constructions. In Wambeek Dutch, both complex and pronominal subjects can be doubled by a pronoun (102a-b).

\footnotetext{
${ }^{48}$ More evidence for this comes from Pankau's observation that speakers who allow relative pronouns in wh-copying may employ these instead, since they do come in matching feminine and plural forms.

${ }^{49}$ Importantly, this means that a form like wer carries a [+masculine] feature that is not interpreted (because $w h$-questions using wer are not restricted to men). This idea receives independent support from the fact that pronouns bound by a wh-phrase must also be masculine in form, as Fanselow et al. (2005) point out, even though no semantic restriction to men is present (ia). Conversely, grammatically feminine pronouns cannot be bound by a wh-phrase (ib).
}
a. Wer Wh $_{\mathrm{i}}$ seinen $\mathrm{i}_{\mathrm{i}}$ Mantel verloren?
who has his coat lost
'Who has lost his coat?'
b. $\quad$ Wer $_{\mathrm{i}}$ hat ihren $_{\mathrm{k} / * \mathrm{i}}$ Mantel verloren?
who has her coat lost
'Who has lost her coat?'
(German; Fanselow et al. 2005:42)

\footnotetext{
${ }^{50}$ One question is why copied pronouns in wh-copying retain wh-morphology, something that is not found in many other pronoun copying constructions. This is presumably linked to the observation that $w h$-copying is typically restricted to $w h$-movement, unlike ké-copying, for example. One option is that $w h$-morphology is in principle deletable (perhaps because it is phrasal in origin), but that wh-copying is driven by the need to express this morphology.
} 
Subject doubling with complex and pronominal subjects in Wambeek Dutch:

a. Dei vrou gui zij.

that woman go she

'That woman is going.'

b. Zij gui zij.

she go she

'She is going.'

(Wambeek Dutch; Van Craenenbroeck and Van Koppen 2002:56)

But in other Dutch dialects, such as the Lapscheure or Brabant dialect, only pronouns participate in copying and never complex DPs. Examples from the Brabant dialect in (103a-b) demonstrate. ${ }^{51}$

Subject doubling only with pronominal subjects in Brabant Dutch:

a. *Die vrau komt zij.

that woman comes she

'That woman will come.'

b. Zij komt zij.

she comes she

'She will come.'

(Brabant Dutch; Van Craenenbroeck and Van Koppen 2002:56)

In these pronoun copying constructions then, a gap arises with complex $w h$-phrases. Multiple copy spell-out is only possible if both DPs are pronouns.

This gap is in fact neatly predicted by the model developed so far. German and Dutch have suppletion for case in pronouns, so are systems in which $n$ cannot be a phase head in pronouns. Suppose now that, for some speakers, all 3rd person pronouns are treated as realizations of both person and number, as I argued for the 3rd person singular pronoun in Dinka. As for Dinka, we could say that this is because the insertion rules for the 3rd person pronouns for these speakers all make reference to person. ${ }^{52}$ This would mean that partial deletion in a lexical DP will never result in a structure that can be realized as a pronoun, because none of the 3rd person pronouns realize only number. When the moved DP is a pronoun, however, no partial deletion applies ( $n$ is not a phase), so that multiple copy spell-out does yield a pronoun.

I do not know of independent evidence for the distinction posited between different speakers of German and Dutch (and presumably there are no overt differences in

\footnotetext{
${ }^{51}$ As Van Craenenbroeck and Van Koppen note, interesting differences emerge between the strong and weak pronouns in pronoun copying too. The copied pronoun is always strong, while dialects vary as to whether the antecedent can be. I hope that this variation could also be made to follow from a partial spell-out approach.

${ }^{52}$ An alternative analytical option, since pronouns in German and Dutch does not show distinct morphemes for person and number in pronouns, like Dinka, would be to say that all pronouns realize person and number jointly, with one morpheme spelling out both NumP and $n \mathrm{P}$. This option is available if we adopt the idea that morphemes can spell out multiple heads, through phrasal spell-out or spanning (e.g. Starke 2009; Ramchand 2008; Bye and Svenonius 2012).
} 
pronoun inventory). As pointed out by an anonymous reviewer, an alternative account of this gap could build on the observation that syntactic processes can be restricted to pronouns. There are other syntactic phenomena that only target pronouns, such as in object shift in the Scandinavian languages and Q-float with English objects (I saw them all vs. *I saw the children all). For such phenomena, we could assume that Nunes's $(1995,2004)$ head-adjunction account is on the right track, for example. In such an account, pronoun copying patterns restricted to pronouns would always involve head-adjunction, and so could not target lexical DPs. ${ }^{53}$

This section has shown that the person mismatch and the singular gap in Dinka have their counterparts in other pronoun copying constructions, so that the effect of partial deletion is evident across languages. This provides evidence for a unified account of multiple copy spell-out, based on subdeletion, with two parameters of variation: (i) the spell-out rules responsible for creating pronouns, and (ii) whether $n$ in pronouns is a phase.

\section{Concluding remarks}

In this paper, I have develop a unified approach to pronoun copying constructions, based on an economy approach to copy deletion (Landau 2006). I demonstrated that copied pronouns display asymmetries and gaps, in a way that reveals the application of partial deletion, so that pronouns that spell out copies show identifiable morphosyntactic differences from 'trueborn' pronouns. If correct, then the syntax of gaps left by movement is not as opaque as sometimes thought. The internal structure of gaps becomes transparent in a range of syntactic contexts and offers direct insight into the structure of DPs, providing evidence that all displacement of DPs involves the formation of copies with an articulated internal structure, as in the Copy Theory of Movement (Chomsky 1995 et seq.). Also, ké-copying functions as an additional argument for successive-cyclic derivations, because it provides evidence for a step of intermediate movement through the $v$ P edge (Chomsky 1986 et seq.). Finally, the approach to pronoun copying defended here shows that person and number are introduced in separate projections within a DP, because they can be separated in copying constructions.

Acknowledgements My thanks to David Hall, Claire Halpert, Sabine Iatridou, Ted Levin, David Pesetsky, Ezer Rasin, and Norvin Richards for comments and discussion, as well as audiences at WCCFL 33 and LAGB 2015, and of talks at MIT, Queen Mary, and Oxford. I am particularly grateful to Nico Baier for extensive conversations about the patterns discussed here. I am indebted to Mangok Bol and Abiar Makoor Guot for sharing their language with me. This research is made possible by an NSF Dissertation Improvement Grant, BCS-1440427.

\footnotetext{
${ }^{53}$ Another reason to think a head-adjunction analysis of certain pronoun copying constructions should not be ruled out may be that it can provide an account of specificity restrictions found in some apparent instances of pronoun copying. For example, it has been argued that clitic doubling may represent another construction in which a pronoun can realize a copy of a lexical DP (e.g. Harizanov 2014; Kramer 2014). However, clitic doubling often shows sensitivity to specificity, unlike the other pronoun copying patterns discussed here. Baker and Kramer (2016) present an analysis of this fact based on the idea that clitic doubling involves a reduced copy that is interpreted as a pronoun at LF. See also Bianchi (2011).
} 
Open Access This article is distributed under the terms of the Creative Commons Attribution 4.0 International License (http://creativecommons.org/licenses/by/4.0/), which permits unrestricted use, distribution, and reproduction in any medium, provided you give appropriate credit to the original author(s) and the source, provide a link to the Creative Commons license, and indicate if changes were made.

\section{References}

Abels, Klaus. 2001. The predicate cleft construction in Russian. In Formal Approaches to Slavic Linguistics (FASL) 9, eds. Steven Franks and Michael Yadroff, 1-19. Bloomington: Michigan Slavic Publications.

Adesola, Oluseye. 2010. The non-agreeing subject resumptive pronoun in Yoruba. In Topics in Kwa syntax, ed. James Essegbey, 65-89. Dordrecht: Springer.

Adger, David. 2011. Bare resumptives. In Resumptive pronouns at the interfaces, ed. Alain Rouveret, 343-366. Amsterdam: Benjamins.

Adger, David. 2013. The syntax of substance. Cambridge: MIT Press.

Anagnostopoulou, Elena. 2003. The syntax of ditransitives: Evidence from clitics. Berlin: de Gruyter.

Andersen, Torben. 1991. Subject and topic in Dinka. Studies in Language 15: 265-294.

Andersen, Torben. 1993. Vowel quality alternation in Dinka verb inflection. Phonology 10: 1-42.

Andersen, Torben. 2002. Case inflection and nominal head marking in Dinka. Journal of African Languages and Linguistics 23: 1-30.

Andersen, Torben. 2007. Auxiliary verbs in Dinka. Studies in Language 31: 89-116.

Andersen, Torben. 2014. Number in Dinka. In Number - Constructions and semantics: Case studies from Africa, Amazonia and Oceania, eds. Anne Storch and Gerrit Dimmendaal, 221-263. Amsterdam: Benjamins.

Andersen, Torben. 2016. Case inflection of construct state constructions in Dinka. Linguistics 54: 639681 .

Baier, Nico. 2014. Spell-out, chains, and long distance wh-movement in Seereer. Paper presented at Chicago Linguistic Society (CLS) 50, Chicago.

Baier, Nico. 2016. Deriving partial anti-agreement. Paper presented at the Linguistic Society of America (LSA) 2016, Washington DC.

Baker, Mark, and Ruth Kramer. 2016. Clitics are pronouns: Reduce and interpret. Ms., Rutgers University and Georgetown University.

Bianchi, Valentina. 2011. Some notes on the 'specificity effects' of optional resumptive pronouns. In $R e$ sumptive pronouns at the interfaces, ed. Alain Rouveret, 319-342. Amsterdam: Benjamins.

Bobaljik, Jonathan. 2012. Universals in comparative morphology: Suppletion, superlatives, and the structure of words. Cambridge: MIT Press.

Bobaljik, Jonathan, and Susi Wurmbrand. 2005. The domain of agreement. Natural Language and Linguistic Theory 23: 809-865.

Boeckx, Cedric. 2003. Islands and chains: Resumption as stranding. Amsterdam: Benjamins.

Bošković, Željko. 2014. Now I'm a phase, now I'm not a phase: On the variability of phases with extraction and ellipsis. Linguistic Inquiry 45: 27-89.

Bošković, Željko. 2015. From the Complex NP Constraint to everything: On deep extractions across categories. The Linguistic Review 32: 603-669.

Bouma, Gosse, Rob Malouf, and Ivan Sag. 2001. Satisfying constraints on extraction and adjunction. Natural Language and Linguistic Theory 19: 1-65.

Brody, Michael. 2000. Mirror Theory: Syntactic representation in perfect syntax. Linguistic Inquiry 31: 29-56.

Bruening, Benjamin. 2006. Differences between wh-scope marking and wh-copy constructions in Passamaquoddy. Linguistic Inquiry 37: 25-49.

Bye, Patrik, and Peter Svenonius. 2012. Non-concatenative morphology as epiphenomenon. In The morphology and phonology of exponence: The state of the art, ed. Jochen Trommer, 427-495. Oxford: Oxford University Press.

Cardinaletti, Anna, and Michal Starke. 1999. The typology of structural deficiency. In Clitics and other functional categories in European languages, ed. Henk van Riemsdijk, 145-234. Berlin: de Gruyter.

Chomsky, Noam. 1981. Lectures on government and binding. Dordrecht: Foris.

Chomsky, Noam. 1986. Barriers. Cambridge: MIT Press. 
Chomsky, Noam. 1995. The minimalist program. Cambridge: MIT Press.

van Craenenbroeck, Jeroen, and Marjo van Koppen. 2002. Subject doubling in Dutch dialects. In ConSOLE 9, eds. Marjo van Koppen, Erica Thrift, Erik Jan van der Torre, and Malte Zimmermann, 54-67.

Déchaine, Rose-Marie, and Martina Wiltschko. 2002. Decomposing pronouns. Linguistic Inquiry 33: 409442.

Elbourne, Paul. 2001. E-type anaphora as NP-deletion. Natural Language Semantics 9: 241-288.

Elbourne, Paul. 2005. Situations and individuals. Cambridge: MIT Press.

Embick, David. 2010. Localism versus globalism in morphology and phonology. Cambridge: MIT Press.

Engdahl, Elisabet. 1982. Restrictions on unbounded dependencies in Swedish. In Readings on unbounded dependencies in Scandinavian languages, eds. Elisabet Engdahl and Eva Ejerhed, 151-174. Stockholm: Almqvist and Wiksell.

Engdahl, Elisabet. 1985. Parasitic gaps, resumptive pronouns, and subject extractions. Linguistics 23: 344.

Evans, Nicholas. 1995. A grammar of Kayardild. Berlin: de Gruyter.

Fanselow, Gisbert, and Anoop Mahajan. 2000. Towards a minimalist theory of $w h$-expletives, $w h$-copying, and successive cyclicity. In Wh-scope marking, eds. Uli Lutz, Gereon Müller, and Arnim von Stechow, 195-230. Amsterdam: Benjamins.

Fanselow, Gisbert, Reinhold Kliegl, and Matthias Schlesewsky. 2005. Syntactic variation in German whquestions. Linguistic Variation Yearbook 5: 37-65.

Felser, Claudia. 2004. Wh-copying, phases, and successive cyclicity. Lingua 114: 543-574.

Fox, Danny, and David Pesetsky. 2005. Cyclic linearization of syntactic structure. Theoretical Linguistics 31: $1-45$.

Gazdar, Gerald. 1981. Unbounded dependencies and coordinate structure. Linguistic Inquiry 12: 155-184.

Greenberg, Joseph. 1963. Some universals of grammar with particular reference to the order of meaningful elements. In Universals of human language, ed. Joseph Greenberg, 73-113. Cambridge: MIT Press.

Gruber, Bettina. 2013. The spatiotemporal dimensions of person: A morphosyntactic account of indexical pronouns. PhD diss., Utrecht University.

Guilliot, Nicolas, and Nouman Malkawi. 2006. When resumption determines reconstruction. In West Coast Conference on Formal Linguistics (WCCFL) 25, eds. Donald Baumer, David Montero, and Michael Scanlon, 168-176. Somerville: Cascadilla Press.

Hale, Ken, and Samuel J. Keyser. 2002. Prolegomenon to a theory of argument structure. Cambridge: MIT Press.

Hall, David. 2015. Spelling out the noun phrase: Interpretation, word order, and the problem of 'meaningless movement'. PhD diss., Queen Mary University of London.

Harbour, Daniel. 2016. Impossible persons. Cambridge: MIT Press.

Harley, Heidi. 2004. Merge, conflation and head movement: The First Sister Principle revisited. In North East Linguistics Society (NELS) 34, eds. Keir Moulton and Matthew Wolf, Amherst: GLSA.

Harizanov, Boris. 2014. Clitic doubling at the syntax-morphophonology interface. Natural Language and Linguistic Theory 32: 1033-1088.

Hartman, Jeremy. 2011. The semantic uniformity of traces: Evidence from ellipsis parallelism. Linguistic Inquiry 42: 367-388.

Holmberg, Anders, and Urpo Nikanne. 2008. Subject doubling in Finnish: The role of deficient pronouns. In Microvariation in syntactic doubling, eds. Sjef Barbiers, Olaf Koeneman, Marika Lekakou, and Margreet van der Ham, 325-349. Amsterdam: Brill.

Johnson, Kyle. 2012. Towards deriving differences in how Wh Movement and QR are pronounced. Lingua 122: 529-553.

Källgren, Gunnel, and Ellen Prince. 1989. Swedish VP-topicalization and Yiddish verb-topicalization. Nordic Journal of Linguistics 12: 47-58.

Kandybowicz, Jason. 2007. The grammar of repetition: Nupe grammar at the syntax-phonology interface. Amsterdam: Benjamins.

Karlsson, Fred. 2015. Finnish: An essential grammar. New York: Routledge.

Koopman, Hilda. 1982. Control from COMP and comparative syntax. Linguistic Review 2: 365-391.

Koopman, Hilda. 1984. The syntax of verbs: From verb movement in the Kru languages to Universal Grammar. Dordrecht: Foris.

Koopman, Hilda, and Dominique Sportiche. 1986. A note on long extraction in Vata and the ECP. Natural Language and Linguistic Theory 4: 357-374.

Kramer, Ruth. 2014. Clitic doubling or object agreement: The view from Amharic. Natural Language and Linguistic Theory 32: 593-634. 
Ladd, D. Robert, Bert Remijsen, and Caguor Adong Manyang. 2009. On the distinction between regular and irregular inflectional morphology: Evidence from Dinka. Language 85: 659-670.

Landau, Idan. 2006. Chain resolution in Hebrew V(P) fronting. Syntax 9: 32-66.

Landau, Idan. 2007. EPP extensions. Linguistic Inquiry 38: 485-523.

McCloskey, Jim. 2006. Resumption. In The Blackwell companion to syntax, eds. Martin Everaert and Henk van Riemsdijk, 94-117. Oxford: Blackwell.

Merchant, Jason. 2008. Variable island repair under ellipsis. In Topics in ellipsis, ed. Kyle Johnson, 132 153. Cambridge: Cambridge University Press.

Moskal, Beata. 2015. Limits on allomorphy: A case study in nominal suppletion. Linguistic Inquiry 46: 363-376.

Neeleman, Ad, and Hans van de Koot. 2010. A local encoding of syntactic dependencies and its consequences for the theory of movement. Syntax 13: 331-372.

Nevins, Andrew. 2011. Multiple agree with clitics: Person complementarity vs. omnivorous number. Natural Language and Linguistic Theory 29: 939-971.

Nunes, Jairo. 1995. The copy theory of movement and linearization of chains in the Minimalist Program. University of Maryland, College Park. PhD diss.

Nunes, Jairo. 2004. Linearization of chains and sideward movement. Cambridge: MIT Press.

Pankau, Andreas. 2013. Replacing copies: The syntax of wh-copying in German. PhD diss., Utrecht University.

Pesetsky, David. 1998. Some optimality principles of sentence pronunciation. In Is the best good enough? eds. Pilar Barbosa, Danny Fox, Paul Hagstrom, Martha McGinnis, and David Pesetsky, 337-383. Cambridge: MIT Press.

Pesetsky, David, and Esther Torrego. 2001. T-to-C movement: Causes and consequences. In Ken Hale: A life in language, ed. Michael Kenstowicz, 355-426. Cambridge: MIT Press.

Postal, Paul. 1969. On so-called 'pronouns' in English. In Modern readings in transformational grammar, eds. David Reibel and Sanford Schane, 201-224. Englewood Cliffs: Prentice-Hall.

Ramchand, Gillian. 2008. Verb meaning and the lexicon: A first phase syntax. Cambridge: Cambridge University Press.

Richards, Norvin. 2001. Movement in language: Interactions and architectures. Oxford: Oxford University Press.

Richards, Norvin. 2016. Contiguity theory. Cambridge: MIT Press.

Sells, Peter. 1984. Syntax and semantics of resumptive pronouns. PhD diss., UMass Amherst.

Sichel, Ivy. 2014. Resumptive pronouns and competition. Linguistic Inquiry 45: 655-693.

Smith, Peter, Beata Moskal, Ting Xu, Jungmin Kang, and Jonathan Bobaljik. 2016. Case and number suppletion in pronouns. Ms., University of Connecticut, Washington University in St. Louis. Available at https://ling.auf.net/lingbuzz/003110. Accessed 19 September 2017.

Starke, Michal. 2009. Nanosyntax: A short primer to a new approach to language. Nordlyd 36: 1-6.

Takahashi, Shoichi, and Danny Fox. 2005. MaxElide and the rebinding problem. In Semantics and Linguistic Theory (SALT) 15, eds. Effi Georgala and Jonathan Howell, 223-240. Ithaca: CLC Publications.

Travis, Lisa. 1984. Parameters and effects of word order variation. PhD diss., MIT.

Trinh, Tue. 2011. Edges and linearization. PhD diss., MIT.

van Urk, Coppe. 2015. A uniform syntax for phrasal movement: A Dinka Bor case study. PhD diss., MIT.

van Urk, Coppe, and Norvin Richards. 2015. Two components of long-distance extraction: Successive cyclicity in Dinka. Linguistic Inquiry 46: 113-155.

Zaenen, Annie, Elisabet Engdahl, and Joan Maling. 1981. Resumptive pronouns can be syntactically bound. Linguistic Inquiry 12: 679-692. 